\title{
Bi-Level Decision-Making Approach for GHG Emissions Control and Municipal Solid Waste Management under Parameter Uncertainty: A Case Study in Beijing, China
}

\author{
Yizhong Chen, Li He*, Hongwei Lu, Jing Li \\ School of Renewable Energy, North China Electric Power University, \\ Beijing 102206, China
}

Received: 16 April 2015

Accepted: 5 December 2015

\begin{abstract}
Greenhouse gas (GHG) emissions from municipal solid waste (MSW) management significantly contribute to high global warming potential (GWP). However, most studies have failed to facilitate identifying MSW management schemes capable of comprehensively meeting the goals from decision-makers at different hierarchical levels under uncertainties. This study develops an inexact bi-level linear programming (IBLP) model for collaborative control of GHG emissions and waste management in Beijing: MGU-MCL. The MGU-MCL model implies a leader-follower decision process, with the environmental sector providing the upper-level objective and the local authority dominating the lower-level objective. Then, an interactive fuzzy possiblistic approach is introduced to represent the satisfactory degrees of different decision-making levels. Results show that the MGU-MCL model decisions would reduce GHG emissions by about $9 \%$, but increase management costs by $4 \%$ compared with the decisions from conventional models; the contribution of the landfill facilities to GHG emissions would be predominant, especially methane emissions; while the composting and incineration facilities would account for a large proportion of management cost. Further comparative analysis among the bi-level and single-level models indicates that the bi-level model could provide coordinated schemes under an integrated consideration of economic efficiency and environmental impact.
\end{abstract}

Keywords: greenhouse gas, waste management, uncertainties, bi-level linear programming, fuzzy possiblistic

*e-mail: li.he@ncepu.edu.cn 


\section{Introduction}

Greenhouse gas (GHG) emissions mitigation, waste resource utilization, and economic cost optimization are placed at the forefront of municipal solid waste (MSW) management [1-4]. In the MSW management system, GHGs are emitted during all disposal processes, including carbon dioxide $\left(\mathrm{CO}_{2}\right)$, nitrous oxide $\left(\mathrm{N}_{2} \mathrm{O}\right)$, and methane $\left(\mathrm{CH}_{4}\right)$ from collection, transportation, and operation processes, which are believed to be the primary reason for global warming potential (GWP) [5-7]. For example, $\mathrm{CH}_{4}$ emissions from landfill facilities have contributed approximately $3-4 \%$ to annual global anthropogenic GHG emissions; $\mathrm{N}_{2} \mathrm{O}$ emissions associated with incineration ranged between 11 and $293 \mathrm{~g}$ of $\mathrm{N}_{2} \mathrm{O} /$ tons of waste, which were estimated to be 298 times more effective than $\mathrm{CO}_{2}$ for their GWP [8]. In Canada, about 25 million tons $\mathrm{CO}_{2}$ equivalent $\left(\mathrm{CO}_{2}\right.$-eq) emissions were produced from the MSW department in 2001, of which landfill facilities accounted for approximately 92\% [9]; in the United States, waste-related activities shared about $2.3 \%$ of total GHG emissions in 2008 [10].

China has surpassed the United States as the world's largest GHG emitter since 2010, accounting for about $32 \%$ of total GHG emissions in 2013 [11]. In response to the challenges of climate mitigation and sustainable development, China has viewed intensifying MSW management as a priority area of GHG emissions control through publishing "China's National Climate Change Program" in 2007 [12]. Accordingly, it is increasingly imperative for decision-makers to explore a sound strategy for collaborative control of GHG emissions and waste management.

Previously, numerous efforts have been taken to explore the inherent relationships between GHG emissions and waste management [13-15]. Based on the Gabi software package, Chang et al. [16] integrated GWP and cost-benefit criteria to identify an optimal strategy of a typical MSW system. Findings indicated that the traditional cost-benefit analysis without GWP concerns could hardly compete with the scheme with GWP concerns. Zhao et al. [17] employed eco-efficiency (E/E), life cycle assessment (LCA), and life cycle costing (LCC) to analyze an MSW management system in terms of GHG emission mitigation. Results showed no linear relationship between global warming impact and the cost impact in the MSW management system.

However, various complexities and uncertainties attributed to spatial and temporal variations may exist in a general MSW management system, which not only place them beyond the conventional deterministic optimization approaches, but also strengthen the conflictladen MSW allocation between competing environmental and municipal interests. To counteract these concerns, it is crucial to allocate WSW under uncertainties through applying mathematical techniques. $\mathrm{Lu}$ et al. [18] introduced a single-objective programming model for developing MSW management strategy under uncertainty. Findings indicated that the model with GHG concerns was more beneficial to the environment, with over 5.5 million tons of total equivalent contribution (TEC) being reduced over the 15-year planning horizon. Additionally, the environmental effects can be transferred from the constraints to an objective function, resulting in the generation of a multi-objective programming problem. An inexact multi-objective dynamic model for MSW management was proposed by Su et al. [19], wherein the environmental effects and waste management cost were considered as the major objectives. A multi-objective programming model was also developed for supporting waste management with consideration of GHG emissions mitigation under uncertainty [20].

Despite the above-mentioned efforts, tradeoffs between management cost and GHG emissions are usually needed because the corresponding decision-makers represent different concerns. Questions could hardly be answered without considering the tradeoffs:

1. How to satisfy the goals of both saving costs and reducing GHG emissions in a sequential manner?

2. How to conduct optimal MSW management strategies to achieve utilization of waste resources?

3. What are the best sizing and timing for facility expansion?

In practical terms, neither single-objective nor multiobjective approaches can address the above issues effectively. Because the two approaches must be satisfied simultaneously, a leader-follower relationship must be maintained. However, the bi-level linear programming (BLP) method provides a potential technique to solve this type of problem. Unlike the conventional multi-objective methods, the BLP method can make a non-compromised decision among different levels, which can address problems wherein two decision makers are at different hierarchical levels - the leader and the follower - with each one not controlling part of the variables but having its objective function and constrains [21].

In the BLP decision-making processes, the follower must follow the leader, which in turn must attempt to meet the follower in an incentive or disincentive manner for their targets to be optimized synchronously [22]. Currently, the BLP method has been applied for the leader-follower problems [23-24]. For instance, He et al. [25] advanced a mixed integer bi-level decision-making method with features like two decision makers at different levels. A bi-level stochastic optimization approach was also developed by Kalashnikov et al. [26] for coping with a natural gas cash-out problem wherein a leader-follower system existed.

Therefore, this study aims to develop an inexact bi-level linear programming model (named as MGU-MCL model) in support of collaborative control of GHG emissions and waste management for the city of Beijing, China. This model is formulated by integrating inexact linear programing (ILP) [27] and bi-level linear programming into a general framework. Moreover, solutions obtained from the MGU-MCL model and the conventional singlelevel programming, namely the minimization of GHG emissions (MGS) and the minimization of management 
cost (MCS) are compared to analyze the changes in decision-making processes from the perspectives of economic, environmental, and system management efficiency.

\section{Materials and Methods}

\section{Overview of the Study System}

Beijing was selected as our case study to illustrate the performance of the approach. The city has an area of $16,410.54 \mathrm{~km}^{2}$. It has a population of approximately 21.14 million, generating more than 18,400 tons of residential waste per day. Four MSW process units, namely transfer station, landfill, composting, and incineration facilities are applied in Beijing. The planning MSW allocation scheme in Beijing is illustrated in Fig. 1. Specifically, 29 MSW treatment facilities are centered, of which six are for transfer stations, 13 for landfill facilities, five for composting, and five for incineration facilities. The most waste that flows from urban districts would be collected and shipped to transfer stations for pretreatment, then allocated to the terminal processing facilities. Because of the lack of a large-scale transit system, the waste flows generated in the suburban areas would be directly sent to the terminal processing facilities, primarily for composting and landfilling.
According to the three-year implementation plan for construction of municipal solid waste treatment and disposal facilities for Beijing, the total percentage of incineration and biological treatment will run up to $70 \%$ before 2015 and that of landfill will decrease to $30 \%$ [11]. Data from this document would be seen as the input data for the MGU-MCL model formulation. Besides, a previous study showed that $\mathrm{CO}_{2}$-eq emissions associated with MSW management activities in Beijing have been increasing since 2010, and are expected to peak at $54,367 \mathrm{~m}^{3} / \mathrm{h}$ around 2026 [11].

\section{Data Collection and Analysis}

The planning span (from 2016 to 2030) was partitioned into three periods, with each one representing five years. Field investigation and data collection from related reports were the primary sources for determining model parameters [28-29]. The investments of MSW management comprised the costs for collection, transportation, operation, air control, and power generation (Table 1). Revenues from transfer stations and composting and incineration facilities could compensate for the huge operational costs. Revenues from a composting facility are assessed through biogas power generation and fertilizer sales. Also, power generation and government subsidies are sources of incineration facility revenues. Table 2 presents the average revenues throughout the planning horizon. Since

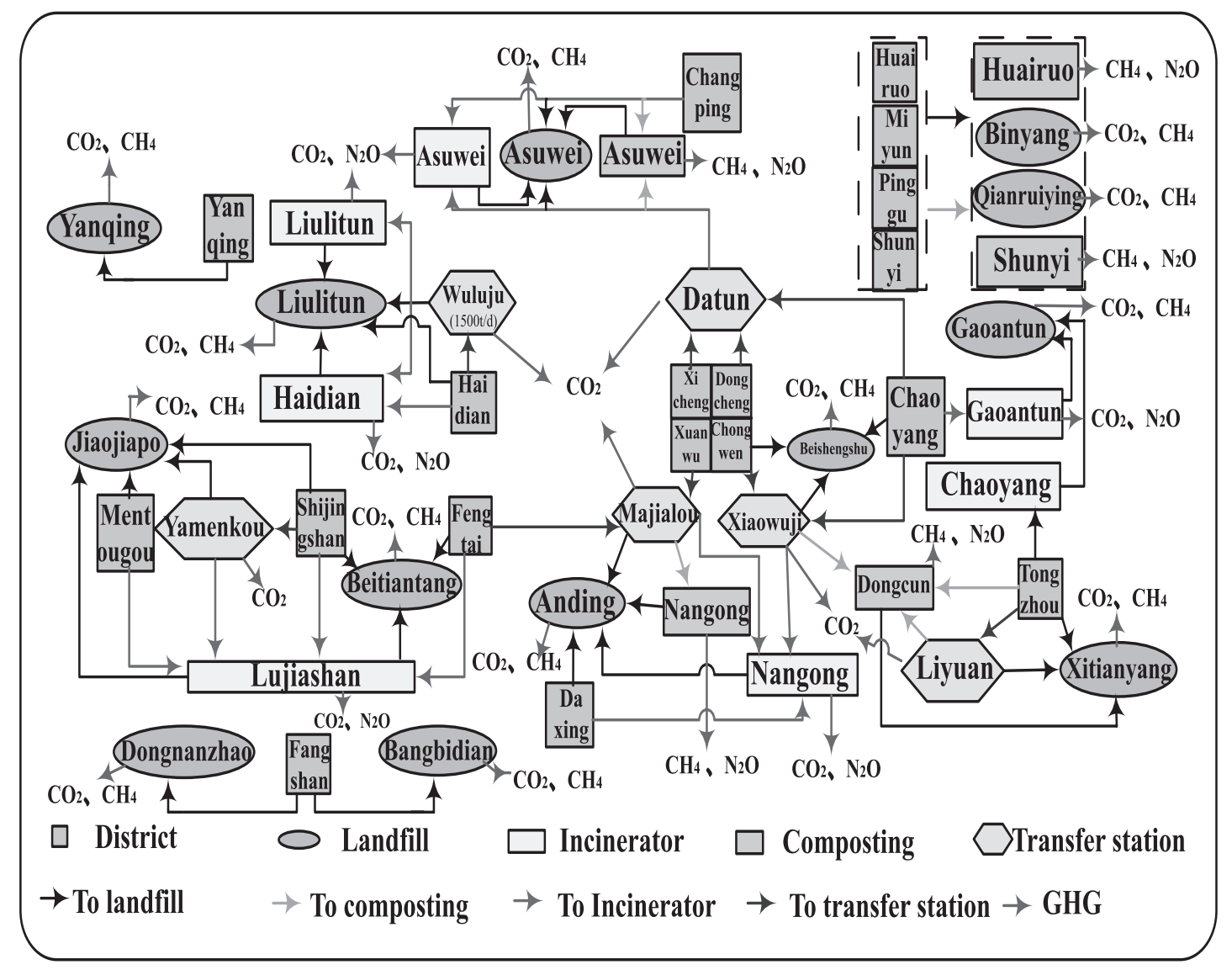

Fig. 1. MSW management system planning in Beijing. 
Table 1. Information about disposal, power generation, and air control.

\begin{tabular}{|c|c|c|c|}
\hline Data & Period 1 & Period 2 & Period 3 \\
\hline \multicolumn{4}{|l|}{ Transfer station operation cost (\$/ton) } \\
\hline$(t=1)$ Yamenkou transfer station & {$[36.45,37.10]$} & {$[38.74,39.86]$} & {$[40.10,42.12]$} \\
\hline$(t=2)$ Wuluju transfer station & {$[34.13,35.64]$} & {$[36.13,38.10]$} & {$[38.14,39.45]$} \\
\hline$(t=3)$ Majialou transfer station & {$[33.11,33.86]$} & {$[34.85,36.48]$} & {$[37.25,38.45]$} \\
\hline$(t=4)$ Xiaowuji transfer station & {$[33.42,34.23]$} & {$[35.46,36.65]$} & {$[37.05,39.31]$} \\
\hline$(t=5)$ Datun transfer station & {$[32.82,34.16]$} & {$[34.21,36.12]$} & {$[36.13,38.15]$} \\
\hline$(t=6)$ Liyuan transfer station & {$[35.64,38.16]$} & {$[37.95,40.26]$} & {$[40.35,42.40]$} \\
\hline \multicolumn{4}{|c|}{ Landfill operation cost (\$/ton) } \\
\hline$(l=1)$ Liulitun landfill & {$[6.13,7.32]$} & {$[7.52,8.13]$} & {$[9.20,9.64]$} \\
\hline$(l=2)$ Gaoantun landfill & {$[5.49,6.40]$} & {$[6.43,8.58]$} & {$[8.62,9.10]$} \\
\hline$(l=3)$ Xitianyang landfill & {$[5.86,7.12]$} & {$[7.15,8.85]$} & {$[9.00,9.62]$} \\
\hline$(l=4)$ Beishengshu landfill & {$[6.00,7.20]$} & {$[7.34,8.62]$} & {$[8.66,10.12]$} \\
\hline$(l=5)$ Anding landfill & {$[7.26,8.64]$} & {$[8.85,9.23]$} & {$[9.60,10.53]$} \\
\hline$(l=6)$ Beitiantang landfill & {$[7.36,8.16]$} & {$[8.24,8.49]$} & {$[8.88,9.56]$} \\
\hline$(l=7)$ Dongnanzhao landfill & {$[5.59,6.41]$} & {$[6.53,8.58]$} & {$[8.72,9.12]$} \\
\hline$(l=8)$ Banbidian landfill & {$[7.88,8.53]$} & {$[8.63,9.40]$} & {$[9.60,10.15]$} \\
\hline$(l=9)$ Binyang landfill & {$\left[\begin{array}{ll}7.85 & 8.22\end{array}\right]$} & {$[8.34,9.02]$} & {$[9.20,9.68]$} \\
\hline$(l=10)$ Qianruiying landfill & {$[7.92,8.53]$} & {$[8.63,9.60]$} & {$[9.80,10.20]$} \\
\hline$(l=11)$ Asuwei landfill & {$[7.96,8.36]$} & {$[8.44,9.23]$} & {$[8.87,9.76]$} \\
\hline$(l=12)$ Yanqing landfill & {$[7.63,8.56]$} & {$[8.86,9.42]$} & {$[9.72,10.13]$} \\
\hline$(l=13)$ Jiaojiapo landfill & {$[7.86,8.16]$} & {$[8.24,9.03]$} & {$[8.67,9.56]$} \\
\hline \multicolumn{4}{|c|}{ Composting operation cost (\$/ton) } \\
\hline$(c=1)$ Huairou composting & {$[20.50,21.60]$} & {$[18.50,19.50]$} & {$[16.00,17.00]$} \\
\hline$(c=2)$ Shunyi composting & {$[20.75,21.00]$} & {$[18.75,19.00]$} & {$[16.75,17.00]$} \\
\hline$(c=3)$ Dongcun composting & {$[19.60,20.60]$} & {$[18.45,19.50]$} & {$[16.30,18.00]$} \\
\hline$(c=4)$ Nangong composting & {$[20.50,21.50]$} & {$[18.50,19.50]$} & {$[16.00,17.00]$} \\
\hline$(c=5)$ Asuwei composting & {$[20.00,21.00]$} & {$[18.50,19.50]$} & {$[16.50,17.50]$} \\
\hline \multicolumn{4}{|c|}{ Incinerator operation cost (\$/ton) } \\
\hline$(i=1)$ Gaoantun incinerator & {$[24.00,25.00]$} & {$[23.50,24.50]$} & {$[21.00,22.00]$} \\
\hline$(i=2)$ Nangong incinerator & {$[23.50,24.50]$} & {$[22.50,23.50]$} & {$[21.50,22.50]$} \\
\hline$(i=3)$ Lujiashan incinerator & {$[24.50,25.50]$} & {$[23.50,25.00]$} & {$[22.50,23.00]$} \\
\hline$(i=4)$ Asuwei incinerator & {$[22.30,23.00]$} & {$[21.50,22.50]$} & {$[21.00,22.00]$} \\
\hline$(i=5)$ Haidian incinerator & {$[23.80,24.50]$} & {$[23.00,24.00]$} & {$[22.50,23.00]$} \\
\hline Biogas power generation $(\$ / \mathrm{kW} \cdot \mathrm{h})$ & {$[0.03,0.06]$} & {$[0.03,0.06]$} & {$[0.03,0.06]$} \\
\hline Incineration power generation $(\$ / \mathrm{kW} \cdot \mathrm{h})$ & {$[0.15,0.20]$} & {$[0.15,0.20]$} & {$[0.15,0.20]$} \\
\hline Composting air control $(\$ / \mathrm{kW} \cdot \mathrm{h})$ & {$[0.52,0.63]$} & {$[0.52,0.63]$} & {$[0.52,0.63]$} \\
\hline Incineration air control $(\$ / \mathrm{kW} \cdot \mathrm{h})$ & {$[0.30,0.35]$} & {$[0.30,0.35]$} & {$[0.30,0.35]$} \\
\hline
\end{tabular}


Table 2. Revenues for waste flows.

\begin{tabular}{|c|c|c|c|c|}
\hline Facility & source & Period 1 & Period 2 & Period 3 \\
\hline \multirow{2}{*}{ Transfer station } & Recycle $(\$ /$ ton$)$ & {$[6.8,7.5]$} & {$[7.0,7.6]$} & {$[7.1,7.7]$} \\
\hline \multirow{3}{*}{ Composting facility } & Recycle $(\$ /$ ton $)$ & {$[4.2,4.6]$} & {$[4.3,4.7]$} & {$[4.3,4.8]$} \\
\cline { 2 - 5 } & Power generation $(\$ / \mathrm{kW} \cdot \mathrm{h})$ & {$[0.20,0.22]$} & {$[0.20,0.22]$} & {$[0.20,0.22]$} \\
\cline { 2 - 5 } & Fertilizer sale $(\$ /$ ton$)$ & {$[10.5,12.5]$} & {$[10.5,12.5]$} & {$[10.5,12.5]$} \\
\hline \multirow{3}{*}{ Incineration facility } & Recycle $(\$ /$ ton $)$ & {$[6.5,7.2]$} & {$[6.6,7.2]$} & {$[6.8,7.5]$} \\
\cline { 2 - 5 } & Power generation $(\$ / \mathrm{kW} \cdot \mathrm{h})$ & {$[0.20,0.22]$} & {$[0.20,0.22]$} & {$[0.20,0.22]$} \\
\cline { 2 - 5 } & Subsidies $(\$ /$ ton $)$ & {$[30.0,33.0]$} & {$[30.0,33.0]$} & {$[30.0,33.0]$} \\
\hline
\end{tabular}

Table 3. Economic data of facility expansions.

\begin{tabular}{|c|c|c|c|c|}
\hline \multirow{2}{*}{ Facility } & \multirow{2}{*}{ expansion options (ton/day) } & \multicolumn{3}{|c|}{ Capital cost for expansion $\left(\$ 10^{6}\right)$} \\
\hline & & Period 1 & Period 2 & Period 3 \\
\hline \multirow{3}{*}{$\begin{array}{l}\text { Transfer } \\
\text { station }\end{array}$} & Option $1(e=1): 300$ & {$[0.04,0.05]$} & {$[0.03,0.04]$} & {$[0.03,0.04]$} \\
\hline & Option $2(e=2): 400$ & {$[0.06,0.07]$} & {$[0.05,0.06]$} & {$[0.05,0.06]$} \\
\hline & Option $3(e=3): 500$ & {$[0.08,0.09]$} & {$[0.07,0.08]$} & {$[0.06,0.07]$} \\
\hline \multirow{3}{*}{ Composting facility } & Option $1(m=1): 300$ & {$[0.40,0.45]$} & {$[0.35,0.40]$} & {$[0.30,0.35]$} \\
\hline & Option $2(m=2): 500$ & {$[0.60,0.65]$} & {$[0.55,0.58]$} & {$[0.45,0.50]$} \\
\hline & Option $3(m=3): 700$ & {$[0.80,0.90]$} & {$[0.75,0.78]$} & {$[0.65,0.70]$} \\
\hline \multirow{3}{*}{$\begin{array}{l}\text { Incineration } \\
\text { facility }\end{array}$} & Option $1(n=1): 400$ & {$[1.20,1.45]$} & {$[1.10,1.35]$} & {$[1.00,1.25]$} \\
\hline & Option $2(n=2): 600$ & {$[1.80,1.95]$} & {$[1.70,1.85]$} & {$[1.60,1.75]$} \\
\hline & Option $3(n=3): 800$ & {$[2.40,2.55]$} & {$[2.30,2.45]$} & {$[2.20,2.35]$} \\
\hline
\end{tabular}

Table 4. Potential value of GHG emissions and environmental standard levels.

\begin{tabular}{|c|c|c|c|}
\hline Date & period 1 & period 2 & period 3 \\
\hline \multicolumn{4}{|c|}{ Process unit GHG emissions ( $\mathrm{kg} \mathrm{CO}_{2}$-eq/ton waste) } \\
\hline Transportation & {$[9.3,9.9]$} & {$[7.4,7.8]$} & {$[6.0,6.5]$} \\
\hline Transfer station & {$[34,40]$} & {$[30,38]$} & {$[28,35]$} \\
\hline Landfill & {$[200,220]$} & {$[180,200]$} & {$[150,165]$} \\
\hline Composting & {$[15,20]$} & {$[15,18]$} & {$[13,15]$} \\
\hline Incineration & {$[50,60]$} & {$[35,40]$} & {$[30,35]$} \\
\hline \multicolumn{4}{|c|}{ Total mass value (ton/day) } \\
\hline $\mathrm{CO}_{2}$ & 60 & 56 & 50 \\
\hline $\mathrm{CH}_{4}$ & 5 & 4.6 & 4.3 \\
\hline $\mathrm{N}_{2} \mathrm{O}$ & 0.55 & 0.51 & 0.45 \\
\hline
\end{tabular}

the capability of existing facilities can hardly satisfy the increasing waste-disposal demands, system expansions are allowed (Table 3). The potential value of GHG emissions and the environmental standard levels for discharging GHGs to the atmosphere are presented in Table 4.

\section{Modeling Formulation}

Upper-level objective: The upper-level objective function for the MGU-MCL model is applied to minimize the GHG emissions as required by the environmental sector of the city. The objective function can be expressed as carbon equivalent emissions from each of the separate processes. 


\section{Min $T G W P^{+}$}

$=\sum_{k=1}^{3} L_{k} \cdot\left(\sum_{t=1}^{6} X T_{t, k}^{ \pm}+\sum_{t=1}^{6} \sum_{l=1}^{13} X L_{t, l, k}^{ \pm}+\sum_{l=1}^{13} X U L_{l, k}^{ \pm}+\sum_{t=1}^{6} \sum_{c=1}^{5} X C_{t, c, k}^{ \pm}+\sum_{c=1}^{5} X U C_{c, k}^{ \pm}\right.$

$\left.+\sum_{i=1}^{6} \sum_{i=1}^{5} X I_{t, i, k}^{ \pm}+\sum_{i=1}^{5} X U I^{ \pm}{ }_{i, k}+\sum_{c=1}^{5} \sum_{l=1}^{13} X R C_{c, l, k}^{ \pm}+\sum_{i=1}^{5} \sum_{l=1}^{13} X R I_{i, l, k}^{ \pm}\right) \cdot G W P_{t r, k}^{ \pm}$

$+\sum_{k=1}^{3} L_{k} \cdot\left(\sum_{t=1}^{6} \sum_{l=1}^{13} X L_{t, l, k}^{ \pm}+\sum_{l=1}^{13} X U L_{l, k}^{ \pm}+\sum_{c=1}^{5} \sum_{l=1}^{13} X R C_{c, l, k}^{ \pm}+\sum_{i=1}^{5} \sum_{l=1}^{13} X R I_{i, l, k}^{ \pm}\right) \cdot G W P_{l, k}^{ \pm}$

$+\sum_{k=1}^{3} L_{k} \cdot\left(\sum_{t=1}^{6} \sum_{c=1}^{5} X C_{t, c, k}^{ \pm}+\sum_{c=1}^{5} X U C_{c, k}^{ \pm}\right) \cdot G W P_{c, k}^{ \pm}+\sum_{t=1}^{6} \sum_{k=1}^{3} L_{k} \cdot X T_{t, k}^{ \pm} \cdot G W P_{t, k}^{ \pm}$

$+\sum_{k=1}^{3} L_{k} \cdot\left(\sum_{t=1}^{6} \sum_{i=1}^{5} X I_{t, i, k}^{ \pm}+\sum_{i=1}^{5} X U I^{ \pm}{ }_{i, k}\right) \cdot G W P_{i, k}^{ \pm}$

Upper-level constraints:

1) Binary constraints: The facility-expansion can only be considered once in each time period, and binary decision variables (i.e., 0 or 1 ) are used to denote whether a facility should be expanded or not.

$$
\begin{gathered}
\sum_{e=1}^{3} Y_{t, e, k} \leq 1, \forall t, k \\
\sum_{m=1}^{3} U_{c, m, k} \leq 1, \forall c, k \\
\sum_{n=1}^{3} Z_{i, n, k} \leq 1, \forall i, k
\end{gathered}
$$

2) GHG-emission constrains: The total GHG emissions from each process unit should satisfy respective environmental standards.

$$
\left(\sum_{t=1}^{6} X L_{t, l, k}^{ \pm}+\sum_{c=1}^{5} X R C_{c, l, k}^{ \pm}+\sum_{i=1}^{5} X R I_{i, l, k}^{ \pm}+X U L_{l, k}^{ \pm}\right) \cdot G W P_{l, k}^{ \pm} \leq T S T_{k}, \forall l, k
$$

$$
\begin{gathered}
\left(\sum_{t=1}^{6} X C_{t, c, k}^{ \pm}+X U C_{c, k}^{ \pm}\right) \cdot G W P_{c, k}^{ \pm} \leq T S T_{k}, \forall c, k \\
\left(\sum_{t=1}^{6} X I_{t, i, k}^{ \pm}+X U I_{i, k}^{ \pm}\right) \cdot G W P_{i, k}^{ \pm} \leq T S T_{k}, \forall i, k
\end{gathered}
$$

Lower-level objective: the lower-level objective function is the economic target for the MSW management system. The economic objective function contains the investment costs (transportation, operation, and generation costs) and the profits from recycling, electricity sales, fertilizer sales, and government subsidies. The model can be formulated as follows:

$$
\text { Min } \quad T C O S T^{ \pm}=\operatorname{In} v^{ \pm}-\operatorname{Pro}^{ \pm}
$$

of which:

$I n v^{ \pm}$

$=\sum_{k=1}^{3}\left\{\sum_{t=1}^{6} X T_{t, k}^{ \pm} \cdot\left(C C^{ \pm}{ }_{k}+T R^{ \pm}{ }_{k}+O T^{ \pm}{ }_{t, k}\right)+\sum_{l=1}^{13} X U L_{l, k}^{ \pm} \cdot\left(C C^{ \pm}{ }_{k}+T R^{ \pm}{ }_{k}+O L_{l, k}^{ \pm}\right)\right.$

$+\sum_{l=1}^{13}\left(\sum_{t=1}^{6} X L_{t, l, k}^{ \pm}+\sum_{c=1}^{5} X R C_{c, l, k}^{ \pm}+\sum_{i=1}^{5} X R I^{ \pm}{ }_{i, l, k}\right) \cdot\left(T R^{ \pm}{ }_{k}+O L_{l, k}^{ \pm}\right)$

$+\sum_{c=1}^{5} X U C_{c, k}^{ \pm} \cdot\left(C C^{ \pm}{ }_{k}+T R^{ \pm}{ }_{k}+O C_{c, k}^{ \pm}\right)+\sum_{t=1}^{6} \sum_{c=1}^{5} X C^{ \pm}{ }_{t, c, k} \cdot\left(T R^{ \pm}{ }_{k}+O C^{ \pm}{ }_{c, k}\right)$

$+\sum_{c=1}^{5}\left(X U C_{c, k}^{ \pm}+\sum_{t=1}^{6} X C_{t, c, k}^{ \pm}\right) \cdot\left(1-F C_{c, k}\right) \cdot \xi \cdot\left(P C E_{c, k}^{ \pm}+G C E_{c, k}^{ \pm}\right)$

$+\sum_{i=1}^{5} X U I_{i, k}^{ \pm} \cdot\left(C C^{ \pm}{ }_{k}+T R^{ \pm}{ }_{k}+O I_{i, k}^{ \pm}\right)+\sum_{t=1}^{6} \sum_{i=1}^{5} X I_{t, i, k}^{ \pm} \cdot\left(T R^{ \pm}{ }_{k}+O I^{ \pm}{ }_{i, k}\right)$

$\left.+\sum_{i=1}^{5}\left(X U I^{ \pm}{ }_{i, k}+\sum_{t=1}^{6} X I_{t, i, k}^{ \pm}\right) \quad\left(1-F I_{i, k}\right) \cdot \Psi \cdot\left(P I E_{i, k}^{ \pm} \quad+G I E_{i, k}^{ \pm}\right)\right\} \cdot L_{k}$

$+\sum_{c=1}^{5} \sum_{m=1}^{3} \sum_{k=1}^{3} F C C_{m, k}^{ \pm} \cdot U_{c, m, k}+\sum_{i=1}^{5} \sum_{n=1}^{3} \sum_{k=1}^{3} F C I_{n, k}^{ \pm} \cdot Z_{i, n, k}+\sum_{t=1}^{6} \sum_{e=1}^{3} \sum_{k=1}^{3} F C T_{e, k}^{ \pm} \cdot Y_{t, e, k}$

Pro ${ }^{ \pm}$

$=\sum_{k=1}^{3}\left\{\sum_{c=1}^{5}\left(X U C_{c, k}^{ \pm}+\sum_{t=1}^{6} X C_{t, c, k}^{ \pm}\right) \cdot\left(1-F C_{c, k}\right) \cdot\left(R C_{c, k}^{ \pm}+\xi \cdot R C E_{k}^{ \pm}+\Omega \cdot P C F^{ \pm}{ }_{k}\right)\right.$

$+\sum_{i=1}^{5}\left(X U I^{ \pm}{ }_{i, k}+\sum_{t=1}^{6} X I_{t, i, k}^{ \pm}\right) \cdot\left(1-F I_{i, k}\right) \cdot\left(R I_{i, k}^{ \pm}+\Psi \cdot R I E_{k}^{ \pm}+G R I^{ \pm}{ }_{k}\right)+\sum_{t=1}^{6} X T_{t, k}^{ \pm}$

$\left.\cdot\left(1-F T_{t, k}\right) \cdot R T_{t, k}^{ \pm}\right\} \cdot L_{k}$

\section{Lower-level Constraints}

1) Capacity constraints: The waste inflows to each process unit must be less than or equal to the maximum design capacity and more than or equal to the minimum amount of processing.

$$
S C_{t} \leq X T_{t, k}^{ \pm} \leq T C_{t}+\sum_{e=1}^{3} \Delta T C \cdot Y_{t, e, k}, \forall t, k
$$

$S L C_{l} \leq \sum_{t=1}^{6} X L_{t, l, k}^{ \pm}+X U L_{l, k}^{ \pm}+\sum_{c=1}^{5} X R C_{c, l, k}^{ \pm}+\sum_{i=1}^{5} X R I_{i, l, k}^{ \pm} \leq T L C_{l}, \forall l, k$

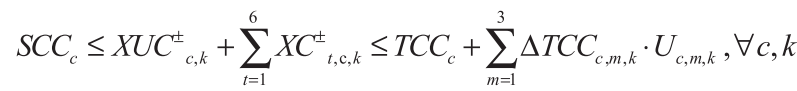

$$
S I C_{i} \leq X U I_{i, k}^{ \pm}+\sum_{t=1}^{6} X I_{t, i, k}^{ \pm} \leq T I C_{i}+\sum_{n=1}^{3} \Delta T I C_{i, n, k} \cdot Z_{i, n, k}, \forall i, k
$$

2) Mass balance constraints: The constraints claim that the total generated waste flows must be less than or equal to the sum of handling amount in the process units. And the waste flows from the transfer station must be equal to the sums of those treated in landfill, composting, and incineration facilities.

$$
\sum_{j=1}^{18} W_{j, k}^{ \pm} \leq T S W_{k}^{ \pm}, \forall k
$$




$$
\begin{aligned}
& \sum_{t=1}^{6} X T_{t, k}^{ \pm}+\sum_{c=1}^{5} X U C_{c, k}^{ \pm}+\sum_{i=1}^{5} X U I^{ \pm}{ }_{i, k}+\sum_{l=1}^{13} X U L_{l, k}^{ \pm}=T S W_{k}^{ \pm}, \quad \forall k \\
& X T_{t, k}^{ \pm} \cdot F T_{t, k}=\sum_{l=1}^{13} X L_{t, l, k}^{ \pm}+\sum_{c=1}^{5} X C_{t, c, k}^{ \pm}+\sum_{i=1}^{5} X I_{t, i, k}^{ \pm}, \forall t, k
\end{aligned}
$$

3) Residue constraints: Residue constraints are needed for composting and incineration facilities. The residue from the facilities must be moved to landfill facilities. According to a particular planning route (Fig. 1), some equations could easily be obtained. For example, the residue from Asuwei composting facility needs to be sent to Asuwei landfill facility for disposal, and the residue generated in Lujiashan incineration facility should be disposed of by Jiaojiapo and Beitiantang landfill facilities, while the composting facilities in suburban areas are not taken into consideration due to their geographical disadvantages.

$$
\begin{aligned}
& \left\{\begin{array}{l}
\sum_{l=1}^{13} X R C^{ \pm}{ }_{c, l, k}=\left(\sum_{t=1}^{6} X{C^{ \pm}}_{t, c, k}^{ \pm}+X U C^{ \pm}{ }_{c, k}\right) \cdot F C_{k}, \forall c, k \\
X R C^{ \pm}{ }_{3,3, k}=\left(X C^{ \pm}{ }_{4,3, k}+X C^{ \pm}{ }_{6,3, k}\right) \cdot F C_{k}, \forall k \\
X R C^{ \pm}{ }_{4,5, k}=X C^{ \pm}{ }_{3,4, k} \cdot F C_{k}, \forall k \\
X R C^{ \pm}{ }_{5,11, k}=\left(X C^{ \pm}{ }_{5,5, k}+X U C^{ \pm}{ }_{5, k}\right) \cdot F C_{k}, \forall k
\end{array}\right. \\
& \left\{\begin{array}{l}
\sum_{l=1}^{13} X R I^{ \pm}{ }_{i, l, k}=\left(\sum_{t=1}^{6} X I_{t, i, k}^{ \pm}+X U I^{ \pm}{ }_{i, k}\right) \cdot F I_{k}, \forall i, k \\
X R I^{ \pm}{ }_{1,2, k}=X U I^{ \pm}{ }_{1, k} \cdot F I_{k}, \forall k \\
X R I^{ \pm}{ }_{2,5, k}=\left(X I^{ \pm}{ }_{4,2, k}+X I^{ \pm}{ }_{3,2, k}+X U I^{ \pm}{ }_{2, k}\right) \cdot F I_{k}, \forall k \\
X R I^{ \pm}{ }_{3,13, k}+X R I^{ \pm}{ }_{3,6, k}=\left(X I^{ \pm}{ }_{1,3, k}+X U I^{ \pm}{ }_{3, k}\right) \cdot F I_{k}, \forall k \\
X R I^{ \pm}{ }_{4,11, k}=\left(X I^{ \pm}{ }_{5,4, k}+X U I^{ \pm}{ }_{4, k}\right) \cdot F I_{k}, \forall k \\
X R I^{ \pm}{ }_{5,1, k}=\left(X I^{ \pm}{ }_{2,5, k}+X U I^{ \pm}{ }_{5, k}\right) \cdot F I_{k}, \forall k
\end{array}\right.
\end{aligned}
$$

4) Constrains of transfer station disposal demand: Waste flows to the transfer stations should be larger than $80 \%$ of those generated in the urban districts, and each transfer station has its respective scope of services. For example, the major scope of Datun transfer station covers (partial or 30\%) Dongcheng, Xicheng, and Chaoyang districts.

$$
\left\{\begin{array}{l}
\sum_{t=1}^{6} X T^{ \pm}{ }_{t, k} \geq G T_{k} \cdot \sum_{j=1}^{8} W_{j, k}^{ \pm}, \forall k \\
X T^{ \pm}{ }_{1, k} \geq W^{ \pm},, \forall k \\
X T^{ \pm}{ }_{2, k} \geq W^{ \pm}{ }_{8, k} \cdot 0.6, \forall k \\
X T^{ \pm}{ }_{3, k}^{ \pm} \geq W^{ \pm}+W^{ \pm}{ }_{6, k} \cdot 0.3, \forall k \\
X T_{4, k}^{ \pm} \geq W_{3, k}^{ \pm}+W_{5, k}^{ \pm} \cdot 0.25, \forall k \\
X T_{5, k}^{ \pm} \geq W_{2, k}^{ \pm}+W_{1, k}^{ \pm}+W^{ \pm} \cdot 0.3, \forall k \\
X T^{ \pm}{ }_{6, k} \geq W_{11, k}^{ \pm}, \forall k
\end{array}\right.
$$

5) Constraints of diversion rate control: As suggested by government documents, at least $30 \%$ and $40 \%$ of the waste should be shipped to the composting and incineration facilities, respectively. And not more than $30 \%$ of the waste should be sent to landfill facilities.

$$
\begin{gathered}
\sum_{c=1}^{5} X U{C^{ \pm}}_{c, k}+\sum_{t=1}^{6} \sum_{c=1}^{5} X{C^{ \pm}}_{t, c, k} \geq G C_{k} \cdot T S{W^{ \pm}}_{k}, \forall k \\
\sum_{i=1}^{5} X U I^{ \pm}{ }_{i, k}+\sum_{t=1}^{6} \sum_{i=1}^{5} X I_{t, i, k}^{ \pm} \geq G I_{k} \cdot T S{W^{ \pm}}_{k}, \forall k
\end{gathered}
$$

$T S W^{ \pm} \cdot G L \min _{k} \leq\left(\sum_{l=1}^{13} X U L_{l, k}^{ \pm}+\sum_{t=1}^{6} \sum_{l=1}^{13} X L_{t, l, k}^{ \pm}\right) \leq T S W_{k}^{ \pm} \cdot G L_{k}, \forall k$

6) Nonnegative constraints: The decision variables should be larger than or equal to zero.

$$
\begin{aligned}
& X T^{ \pm}{ }_{t, k} \geq 0 \quad X L_{t, l, k}^{ \pm} \geq 0 \quad X U L_{l, k}^{ \pm} \geq 0 \quad X C_{t, c, k}^{ \pm} \geq 0 \\
& X U C_{c, k}^{ \pm} \geq 0 \quad X I_{t, i, k}^{ \pm} \geq 0 \quad X U I^{ \pm}{ }_{i, k} \geq 0
\end{aligned}
$$

Detailed nomenclature for indexes, parameters, and variables are presented in the appendix.

\section{Modeling Solution}

According to the fuzzy possibilistic approach and the interactive solution algorithm [30-33], the model can be solved as follows:

First, the upper-level objective (i.e., Eq. 1) solves its problem independently, regardless of lower-level objectives (i.e., Eqs. 4a, 4b, 4c). An interactive solution algorithm is given to address the above issue. In detail, the upper-level objective must be transformed into two deterministic interactive sub-models. Then the lower- and upper-bound GHG emissions (assumed as $\left.\left[T G W P^{-}{ }_{\text {ideal }}, T G W P^{+}{ }_{\text {ideal }}\right]\right)$ can be combined, respectively. And the lower- and upper-bound solutions of daily waste flows can also be generated, namely $\left[X_{\text {upper }}, X^{+}{ }_{\text {upper }}\right]$.

Similarly, the lower-level objective must solve its problem independently, regardless of the upper-level model. The lower- and upper-bound management costs can be generated (assumed to be $\left[T C O S T_{\text {ideal, }}\right.$ TCOST $\left.^{+}{ }_{\text {ideal }}\right]$ ), respectively. And the lower- and upper-bound solutions of daily waste flows, namely $\left[X_{\text {lower }}^{-} X^{+}{ }_{\text {lower }}\right]$, can also be obtained from the lower-level model. If $\left[X_{\text {upper, }}^{-} X^{+}{ }_{\text {upper }}\right]=$ $\left[X_{\text {lower, }} X_{\text {lower }}^{+}\right]$, an optimal solution is achieved. However, their solutions differ because of the dissimilarity between the objectives of the two levels.

Second, the upper-level objective must reassess its tolerances by assuming that the value of $T G W P^{-}\left(T G W P^{+}\right)$ must be around $T G W P^{-}$ideal $\left(T G W P^{+}\right.$ideal $)$. In other words, the most desirable decision is at $T G W P^{-}{ }_{\text {ideal }}\left(T G W P^{+}{ }_{\text {iddeal }}\right)$ and the most undesirable decision at the boundary of 
the interval. The boundary is named as $T G W P_{\text {bound }}^{-}$and $T G W P^{+}{ }_{\text {bound }}$. Decisions outside the lower- or upper-bound intervals are unacceptable.

Third, it must explore the accurate values of the $T G W P^{-}$bound and $T G W P^{+}{ }_{\text {bound }}$. The above-mentioned $\left[X_{\text {upper, }}^{-}\right.$ $\left.X^{+}{ }_{\text {upper }}\right]$ and $\left[X_{\text {lower, }}^{-} X^{+}{ }_{\text {lower }}\right]$ are obtained from solving the two single-level models, respectively. Given that the upper-level objective and the lower-level objective are the exact opposite, the solutions from the lower-level model can then be regarded as the boundary of the upper-level objective. So, $T G W P^{-}$bound can be generated by introducing $X_{\text {lower }}$ to the upper-level objective function and the corresponding $T G W P^{+}$bound can be generated in the same way. Four accurate values can be given through the above steps, namely $T G W P_{\text {ideal }}^{-}, T G W P_{\text {ideal }}^{+}, T G W P_{\text {bound }}^{-}$, and $T G W P^{+}{ }_{\text {bound }}$.

Fourth, it is to regroup the intervals and the results can be shown as $\left[T G W P^{-}{ }_{\text {ideal }}, T G W P_{\text {bound }}^{-}\right]$and $\left[T G W P^{+}\right.$ideal, $\left.T G W P^{+}{ }_{\text {bound }}\right]$. Then the completed set of bounds can be seen as the input parameters in the formulation of the final upper-level membership function.

Fifth, the triangular membership functions of the upper-level objective can be formulated as follows:

$$
\left\{\begin{array}{l}
\alpha^{-}{ }_{\text {upper }}=\frac{\left(T G W P_{\text {bound }}^{-}-T G W P^{-}\right)}{\left(T G W P_{\text {bound }}^{-}-T G W P^{-}{ }_{\text {ideal }}\right)} \\
\alpha^{+}{ }_{\text {upper }}=\frac{\left(T G W P^{+}{ }_{\text {bound }}-T G W P^{+}\right)}{\left(T G W P_{\text {bound }}^{+}-T G W P^{+}{ }_{\text {ideal }}\right)}
\end{array}\right.
$$

$\ldots$ where $\alpha_{\text {upper }}^{-}$and $\alpha^{+}$upper are the lower- and upper-bound satisfactory degrees of upper-level objective, respectively.

Sixth, similar to the solution procedures of the upperlevel objective, the lower-level objective also reassesses its tolerances. The lowest tolerable targets for the lowerlevel objective are named as TCOST ${ }_{\text {bound }}$ and $T C O S T^{+}{ }_{\text {bound }}$, which are calculated by introducing the upper-level solutions (i.e., $\left[X_{\text {upper, }}^{-} X^{+}{ }_{\text {upper }}\right]$ ) to the lower-level objective function. Then to regroup the intervals and the results can

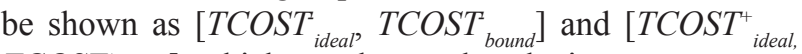
$\mathrm{TCOST}^{+}{ }_{\text {bound }}$ ], which are also used as the input parameters in the formulation of the final lower-level membership function. Thus, the membership function for the goals of the lower-level objective can be stated as:

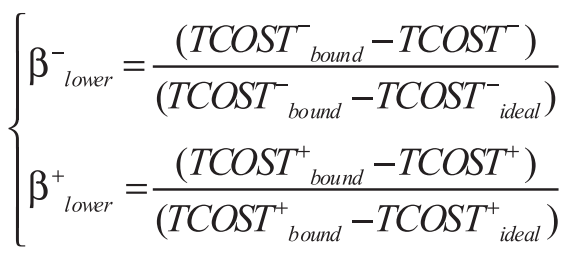

$\ldots$ where $\beta_{\text {lower }}^{-}$and ${\beta^{+}}_{\text {lower }}$ are the lower- and upper-bound satisfactory degrees of lower-level objective, respectively.

Seventh, to satisfy all satisfactory degrees that are usually in conflict with one another, $\alpha_{\text {upper }}^{-}\left(\alpha_{\text {upper }}^{+}\right)$and $\beta_{\text {lower }}^{-}\left(\beta_{\text {lower }}^{+}\right)$must be maximized simultaneously, giving rise to a multi-objective programming problem:

$$
\operatorname{Max}\left\{\alpha^{ \pm}{ }_{\text {upper }}, \beta^{ \pm}{ }_{\text {lower }}\right\}
$$

The fuzzy possibilistic approach is one of the most attractive and practical tools for solving the multiobjective problem. To simplify the problem, the concept of intersection is used, wherein $\lambda^{ \pm}$is defined as [34]:

$$
\lambda^{ \pm}=\operatorname{Min}\left\{\alpha_{\text {upper }}^{ \pm}, \beta^{ \pm}{ }_{\text {lower }}\right\}
$$

... where

$\lambda^{-}=\operatorname{Min}\left\{\alpha_{\text {upper }}^{-}, \beta_{\text {lower }}^{-}\right\}, \lambda^{+}=\operatorname{Min}\left\{\alpha_{\text {upper }}^{+}, \beta^{+}{ }_{\text {lower }}\right\}$

Then the above problem becomes:

$$
\operatorname{Max} \quad \lambda^{ \pm}
$$

Finally, the model becomes:

$$
\left\{\begin{array}{l}
\text { Max } \quad \lambda^{ \pm} \\
\text {s.t. } \\
\lambda^{ \pm}=\operatorname{Min}\left\{\alpha_{\text {upper }}^{ \pm}, \beta_{\text {lower }}^{ \pm}\right\} \\
\alpha_{\text {upper }}^{ \pm}=\frac{\left(T G W P_{\text {bound }}^{ \pm}-T G W P^{ \pm}\right)}{\left(T G W P_{\text {bound }}^{ \pm}-T G W P^{ \pm}{ }_{\text {ideal }}\right)} \\
\beta_{\text {lower }}^{ \pm}=\frac{\left(T C O S T_{\text {bound }}^{ \pm}-T C O S T^{ \pm}\right)}{\left(T C O S T_{\text {bound }}^{ \pm}-T C O S T^{ \pm}{ }_{\text {ideal }}\right)} \\
\text { all contrains }(2 a-10)
\end{array}\right.
$$

Through the interactive solution algorithm, the optimal solutions for the MGU-MCL model can be generated, as follows:

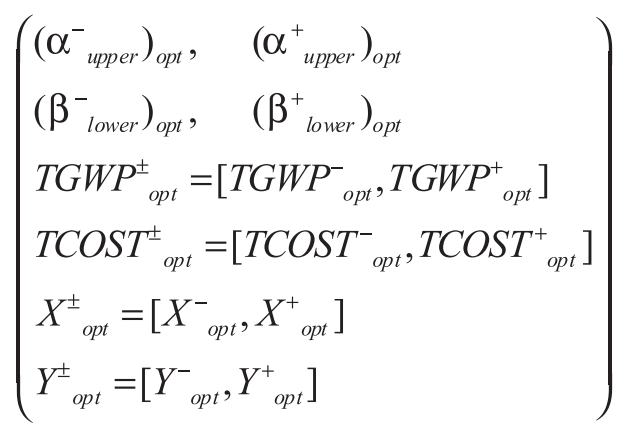

$\ldots$ where $\left(\alpha_{\text {upper }}^{-}\right)_{\text {opt }}$ and $\left(\alpha^{+}{ }_{\text {upper }}\right)_{\text {opt }}$ are the optimized lowerand upper-bound satisfactory degrees of the upper-level objective, respectively; $\left(\beta_{\text {lower }}^{-}\right)_{\text {opt }}$ and $\left(\beta^{+}{ }_{\text {lower }}\right)_{\text {opt }}$ are the optimized lower- and upper-bound satisfactory degrees of the lower-level objective, respectively; $T G W P_{\text {opt }}^{-}$and $T G W P^{+}{ }_{\text {opt }}$ are the optimized lower- and upper-bound $\mathrm{GHG}$ 
emissions, respectively; $T C O S T_{o p t}$ and $T C O S T^{+}{ }_{o p t}$ are the optimized lower- and upper-bound management costs, respectively; $X_{\text {opt }}$ and $X_{\text {opt }}^{+}$represent the optimized lowerand upper-bound daily waste flow-allocation schemes, respectively; $Y_{o p t}$ and $Y_{o p t}^{+}$stand for the optimized lower- and upper-bound capacity-expansion schemes, respectively.

\section{Results Analysis}

\section{Results from MGU-MCL Model}

1) Satisfactory degree analysis. The MGU-MCL model is solved to obtain the maximum satisfactory degree $\left(\lambda_{\text {opt }}^{ \pm}\right)$under uncertainties. The $\lambda$ levels range from 0 to 1 . The $\lambda$ levels near 1 suggest that the solution has a higher possibility to satisfy the objective function value and constraints under more favorable system situations; in contrast, the $\lambda$ levels closer to 0 indicate that the objective function value and constraints with a lower possibility can be met [35]. Under the lowerbound membership function, the economic cost would amount to $\$ 57.3 \times 10^{8}$ and the resulting GHG emissions would reach $0.837 \times 10^{7}$ tons $\mathrm{CO}_{2}$-eq, with $\lambda_{\text {opt }}^{-}=0.50$. Conversely, on the upper-bound membership function side, its economic cost and GHG emissions would respectively run up to $\$ 85.5 \times 10^{8}$ and $0.946 \times 10^{7}$ tons $\mathrm{CO}_{2}$-eq, with $\lambda^{+}{ }_{\text {opt }}=0.57$. Generally, solutions of the objective functions respectively offer two extremes of GHG emissions and economic cost over the 15-year span. As the actual values vary within their lower- and upper-bound extremes, correspondingly, the expected GHG emissions and economic costs would change with varied satisfactory degrees [36].
2) Planning MSW management and GHG emissions: The total quantity of MSW generation in Beijing is presented in Fig. 2. It would respectively reach $[34.33,35.70] \times 10^{6},[35.96,36.33] \times 10^{6}$, and [36.67, $38.02] \times 10^{6}$ tons in periods 1,2 , and 3 , with a high level of diversion rate. Take period 1 for an example, where $[8.97,9.78] \times 10^{6}$ tons waste steams (involving residues) would be allocated to the landfill facilities, whereas $12.31 \times 10^{6}$ and $[13.72,14.28] \times 10^{6}$ tons waste flows would be treated by composting and incineration facilities, respectively.

The concept of carbon equivalent emissions is introduced in this case to identify GWP impacts of $\mathrm{CO}_{2}$, $\mathrm{CH}_{4}$, and $\mathrm{N}_{2} \mathrm{O}$. There would be $[34.36,37.00] \times 10^{5}$ tons $\mathrm{CO}_{2}$-eq of $\mathrm{CO}_{2},[36.71,38.02] \times 10^{5}$ tons $\mathrm{CO}_{2}$-eq of $\mathrm{CH}_{4}$, and $[26.96,27.90] \times 10^{5}$ tons $\mathrm{CO}_{2}$-eq of $\mathrm{N}_{2} \mathrm{O}$ emissions from waste-related processes throughout the planning horizon (Table 5). Even with strict control over landfilling, the proportion of $\mathrm{CH}_{4}$ emissions would also be the largest, which would be responsible for $37.4 \%, 35.1 \%$, and $39.6 \%$ of total GHG emissions by periods 1,2 , and 3, respectively. In terms of the $\mathrm{CO}_{2}$ emissions, landfill and incineration facilities would be the most significant sources for contributing this emission, particularly the former ones, having shares of $60.4 \%, 61.0 \%$, and $60.5 \%$ of total $\mathrm{CO}_{2}$ emissions in periods 1,2 , and 3, respectively. Apart from $\mathrm{CH}_{4}$ and $\mathrm{CO}_{2}$, the effects of $\mathrm{N}_{2} \mathrm{O}$ from incineration facilities could hardly be neglected. The average GWP impact share of $\mathrm{N}_{2} \mathrm{O}$ would respectively be $26.4 \%, 29.3 \%$, and $27.0 \%$ in periods 1,2 , and 3. Temporally, period 2 has the lowest GHG emissions compared with periods 1 $\left([33.64,35.85] \times 10^{5}\right.$ tons $\mathrm{CO}_{2}$-eq) and 3 ([34.16, 35.71] $\times 10^{5}$ tons $\mathrm{CO}_{2}$-eq), which would be attributed to that only $[20.55,21.14] \%$ of the total waste flows are treated by landfilling during period 2.
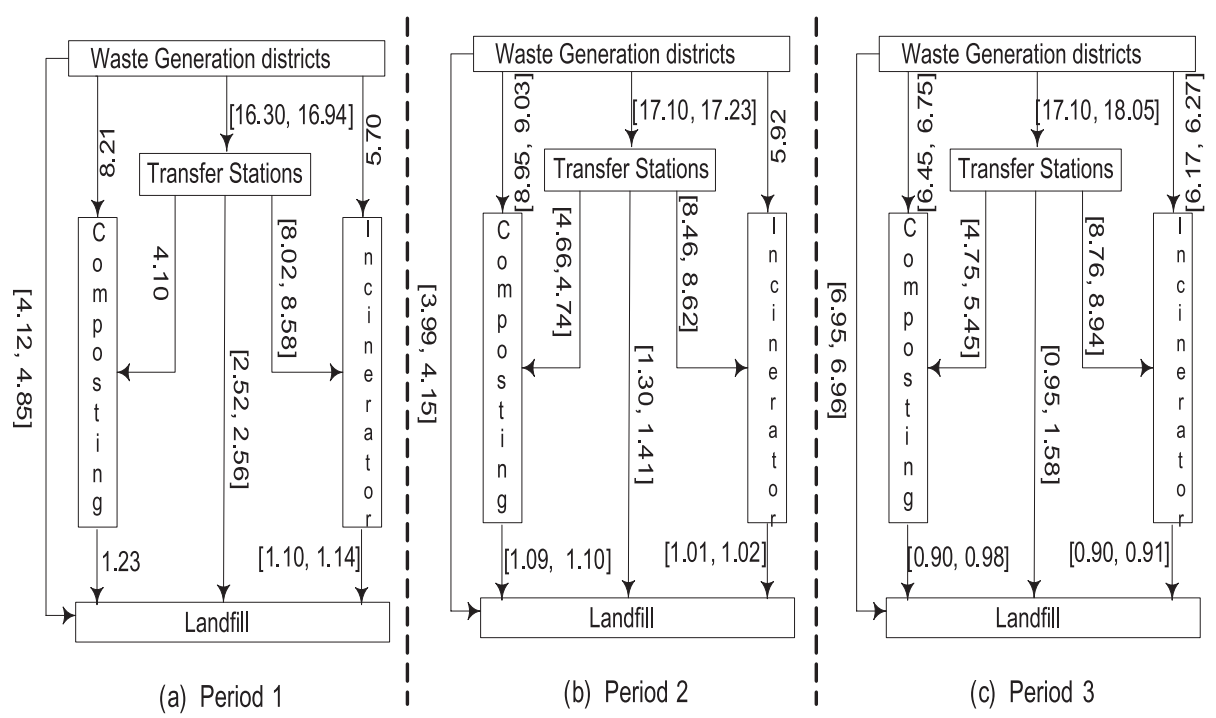

(b) Period 2

(c) Period 3

Fig. 2. Total waste flows consumed by the MSW processes units (Unit: million tons). 
Table 5. Solutions of the MGU-MCL for GHG emissions (unit: $10^{5}$ tons $\mathrm{CO}_{2}$-eq).

\begin{tabular}{|c|c|c|c|c|c|}
\hline \multicolumn{2}{|c|}{ Period 1 } & \multicolumn{2}{|c|}{ period 2 } & \multicolumn{2}{c|}{ period 3 } \\
\hline $\mathrm{GHG}$ & System GWP & GHG & System GWP & GHG & System GWP \\
\hline $\mathrm{CO}_{2}$ & {$[12.16,13.28]$} & $\mathrm{CO}_{2}$ & {$[10.77,11.45]$} & $\mathrm{CO}_{2}$ & {$[11.43,12.27]$} \\
\hline $\mathrm{CH}_{4}$ & {$[12.59,13.52]$} & $\mathrm{CH}_{4}$ & {$[10.60,10.68]$} & $\mathrm{CH}_{4}$ & {$[13.52,13.82]$} \\
\hline $\mathrm{N}_{2} \mathrm{O}$ & {$[8.89,9.05]$} & $\mathrm{N}_{2} \mathrm{O}$ & {$[8.86,9.23]$} & $\mathrm{N}_{2} \mathrm{O}$ & {$[9.21,9.62]$} \\
\hline
\end{tabular}

3) Scenarios and sensitivity analysis. Diversion rate and GWP impact value were estimated in terms of local MSW management policies and the composition of the MSW. Nevertheless, uncertainties may be a critical issue with respect to practical application of the developed MGU-MCL model. Thus, scenarios and sensitivity analysis are needed to identify variations of model solutions to different input factors (i.e., GL, GC, GI, and GWP in the model). In this study diversion rates of $0.70,0.55$, and 0.45 are selected for scenarios 1,2 , and 3 , respectively. Each of the scenarios is designed to be associated with variation of GWP impact values changed by $-20 \%$ to $20 \%$.

Figs 3 and 4 respectively present the impacts of GL, GC, GI, and GWP of the city's MSW toward the GHG emissions and economic cost, where only the lower-

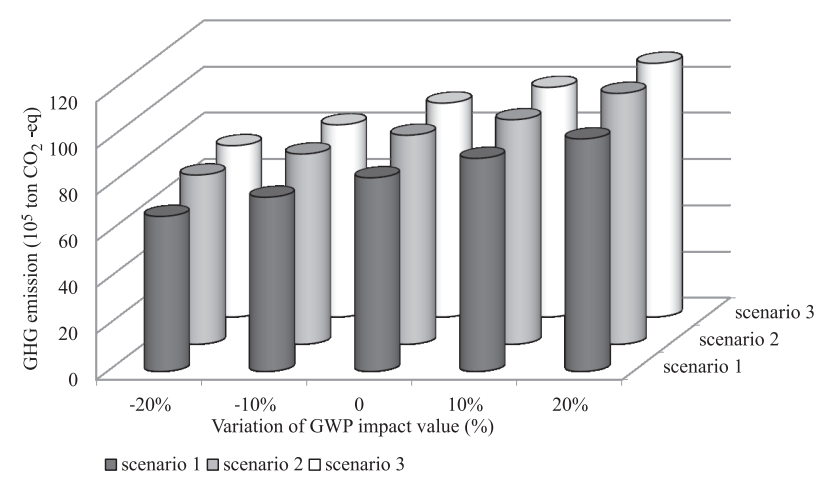

Fig. 3. Variation of GHG emissions versus variation of GWP impact value under different scenarios (Unit: $10^{5}$ ton $\mathrm{CO}_{2}$-eq).

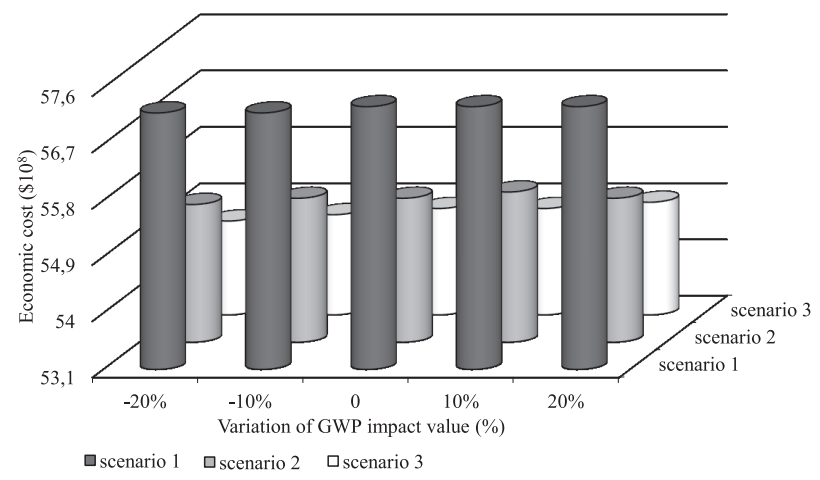

Fig. 4. Variation of economic cost versus variation of GWP impact value under different scenarios (Unit: $\$ 10^{8}$ ). bound situation is taken into consideration. In terms of Fig. 3, the diversion rate and GWP impact value would have a significant impact on system GHG emissions, which would increase with GWP impact value, whereas they decline with diversion rate. The results reveal that when the diversion rate increases $1 \%$, the GHG emissions could approximately be reduce with $0.003 \times 10^{4}$ tons $\mathrm{CO}_{2}^{-}$ eq. Conversely, each decrease of $1 \%$ GWP impact value would lead to a reduction of $0.008 \times 10^{4}$ tons $\mathrm{CO}_{2}$-eq of GHG emissions. Fig. 4 shows that the total economic cost is not sensitive to the variation of GWP impact value, as any chance of GWP impact value could not lead to a minor variation in the total economic cost. However, reducing the diversion rate would play a positive role in economic cost, showing that each reduction of $1 \%$ diversion rate would be attributed to a reduction of $\$ 0.006 \times 10^{8}$ of economic cost. In general, scenarios and sensitivity analysis results indicate that the uncertainties over diversion rate and GWP impact value would have significant impacts on MSW management policies.

\section{Comparisons with MGS and MCS Models}

Multiple difficulties exist in comparing the modeling values to practical ones since the decision is made within a 15-year span [25]. Thus, two single-level models are applied for comparing the modeling values obtained from the bi-level model to those obtained through the singlelevel models.

1) Waste diversion analysis. The waste-flow allocation schemes are shown in Fig. 5. For the MGS scheme, the diversion rate is expected to be $78 \%$, of which composting facilities are responsible for $38 \%$, which significantly exceeds their preset diversion rate (i.e., $30 \%$ ). Oppositely, the existing landfill facilites would dispose of only $22 \%$ of the generated waste flows due to their high GHG emissions. The waste-flow allocation scheme, in terms of MCS model, shows that about $29 \%$ of the total waste would be treated in landfill facilities, which basically achieves their maximum requirement. The above comparative analysis suggests that if GHG emissions were not considered, landfill facility would be used on a large scale because of its competive operation cost. Additionally, the two single-level models have the least diversified targets that narrowly focus on either environmental benefit or economic cost. As a result, their schemes are characterized as either economically aggressive or environmentally 

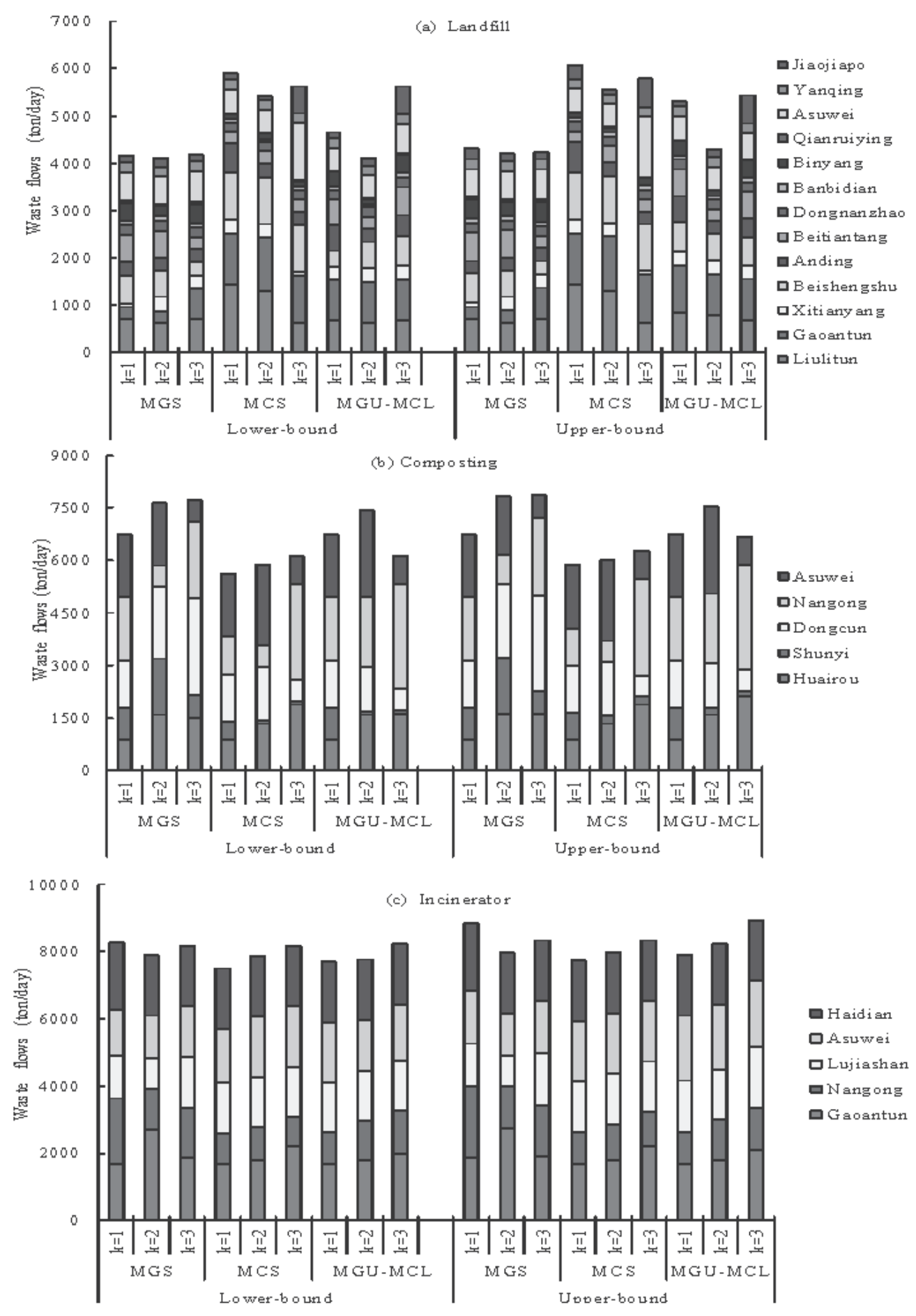

Fig. 5. Waste-flow comparisons among three models (Unit: tons/day).

aggressive. However, by emphasizing both environmental benefit and economic cost, the MGUMCL solutions would provide a more comprehensive waste diversion scheme. Consequently, the facilities that have low GHG emissions and low economic cost would attach more significance.

(2) Facility expansion analysis. The facility-expansion schemes are exhibited in Fig. 6. Given the adjustment of MSW management policy in Beijing, landfill facilities would not be expanded during the entire planning horizon. The transfer stations would dispose of a greater amount of waste flows as the growing waste generation in urban districts. The corresponding expansion for transfer stations would be conducted in terms of the three models (MGS, MCS, and MGUMCL), with the additional daily capacities of 2,400 , 2,300 , and 1,500 tons at the end of period 3 through the three models, respectively. Expansion for composting facilities would also be required in periods 1,2 , and 3 , attributed to their economic and environmental 
advantages. Take the MGU-MCL model as an example, the capacity-expansion of Shunyi and Dongcun composting facilities must be conducted in period 1 , that of Nangong in periods 1 and 3, and that of Huairou and Awuwei in periods 1 and 2. Eventually, these composting facilities' daily capacities would grow to $900,1,350,2,500,1,600$, and 2,600 tons, respectively. The expansion capacities of the incineration facilities would achieve 2,000 and 1,400 tons at the end of period 3 based on the MGS and MGU-MCL models, respectively, yet it would be only 600 tons in terms of the MCS model. This means that the majority of the waste would be shipped to incineration facilities to improve the diversion rate so as to mitigate $\mathrm{GHG}$ emissions.

(3) Environmental effects analysis. Findings show that the MCS scheme would contribute to the lowest GHG emissons reduction, running up to $[0.910,1.020]$ $\times 10^{7}$ tons $\mathrm{CO}_{2}$-eq throughout the 15 -year planning span. Conversely, the MGS scheme - with the best environmental benefits - would result in [0.782, 0.892] $\times 10^{7}$ tons $\mathrm{CO}_{2}$-eq $\left(0.128 \times 10^{7}\right.$ tons $\mathrm{CO}_{2}$-eq lower than that of the MCS scheme). Considering the tradeoffs between GHG-emission control and economic cost minimization, the ideal solution $\left([0.837,0.946] \times 10^{7}\right.$ tons $\mathrm{CO}_{2}$-eq) is found in the MGU-MCL scheme. On the treatment technology side, the landfill facility would make the largest contribution to GHG emissions, accounting for $[46.86,49.80] \%,[51.69,54.48] \%$, and $[56.47,58.90] \%$ in the MGS, MGU-MCL, and MCS, respectively.

The contribution from incineration facilities can hardly be overlooked. Their GWP share would be [19.57, $21.55] \%,[21.57,24.40] \%$, and $[18.02,19.64] \%$ in the MGU-MCL, MGS, and MCS, respectively. Conversely, the GWP impacts of composting would be the lowest. Generally, the MGS provides an environmental-aggressive scheme for cutting GHG emissions to the greatest extent, whereas the GHG-emission from the MGU-MCL scheme would be less than that from the MCS scheme.

On the other hand, landfill facility is not only the main pathway for emitting $\mathrm{CH}_{4}$, but also a major source of $\mathrm{CO}_{2}$ emissions (another is incineration facility). While the contribution of composting and incineration facilities

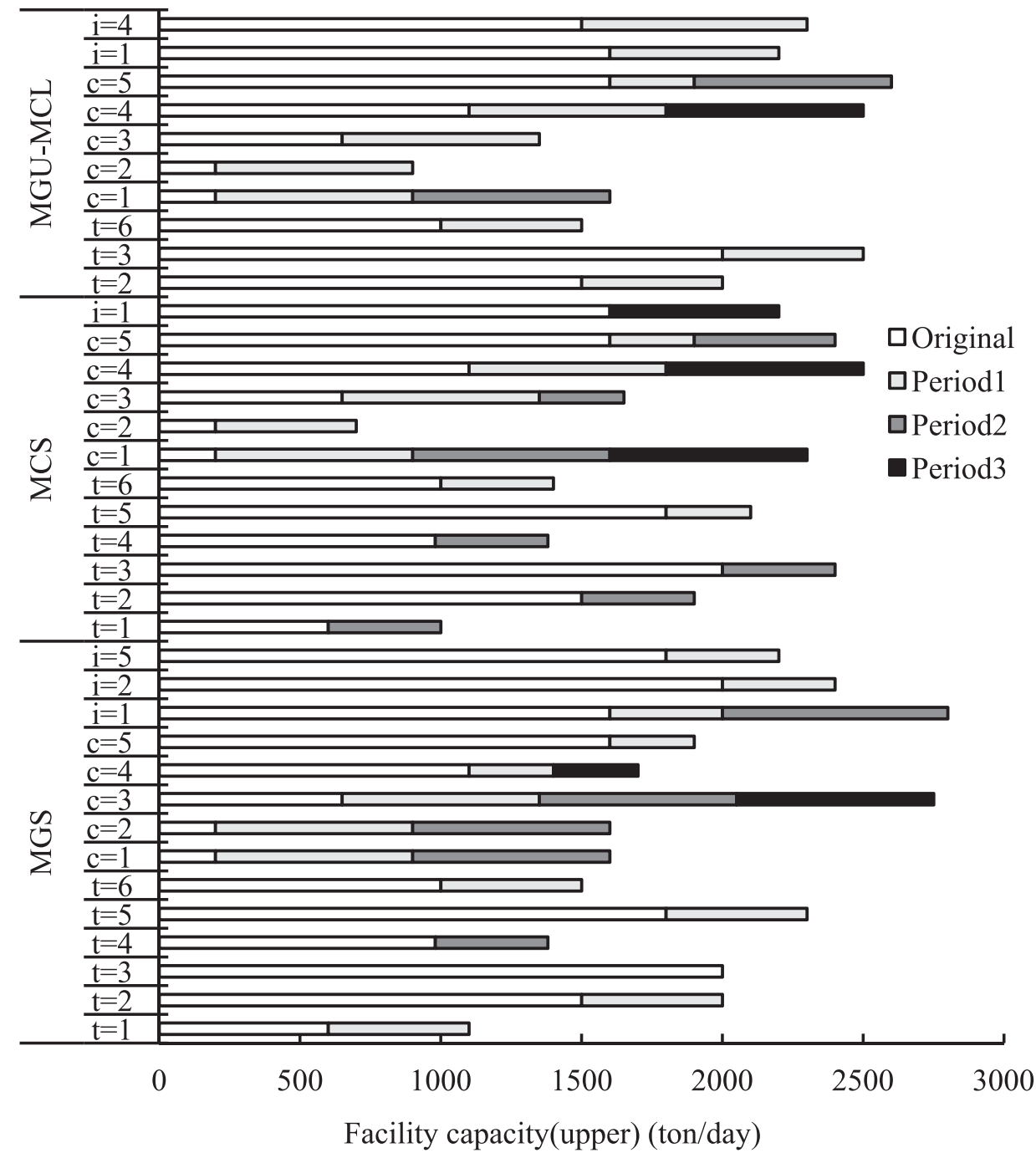

Fig. 6. Facility-expansion (upper) under different models (Unit: tons/day). 


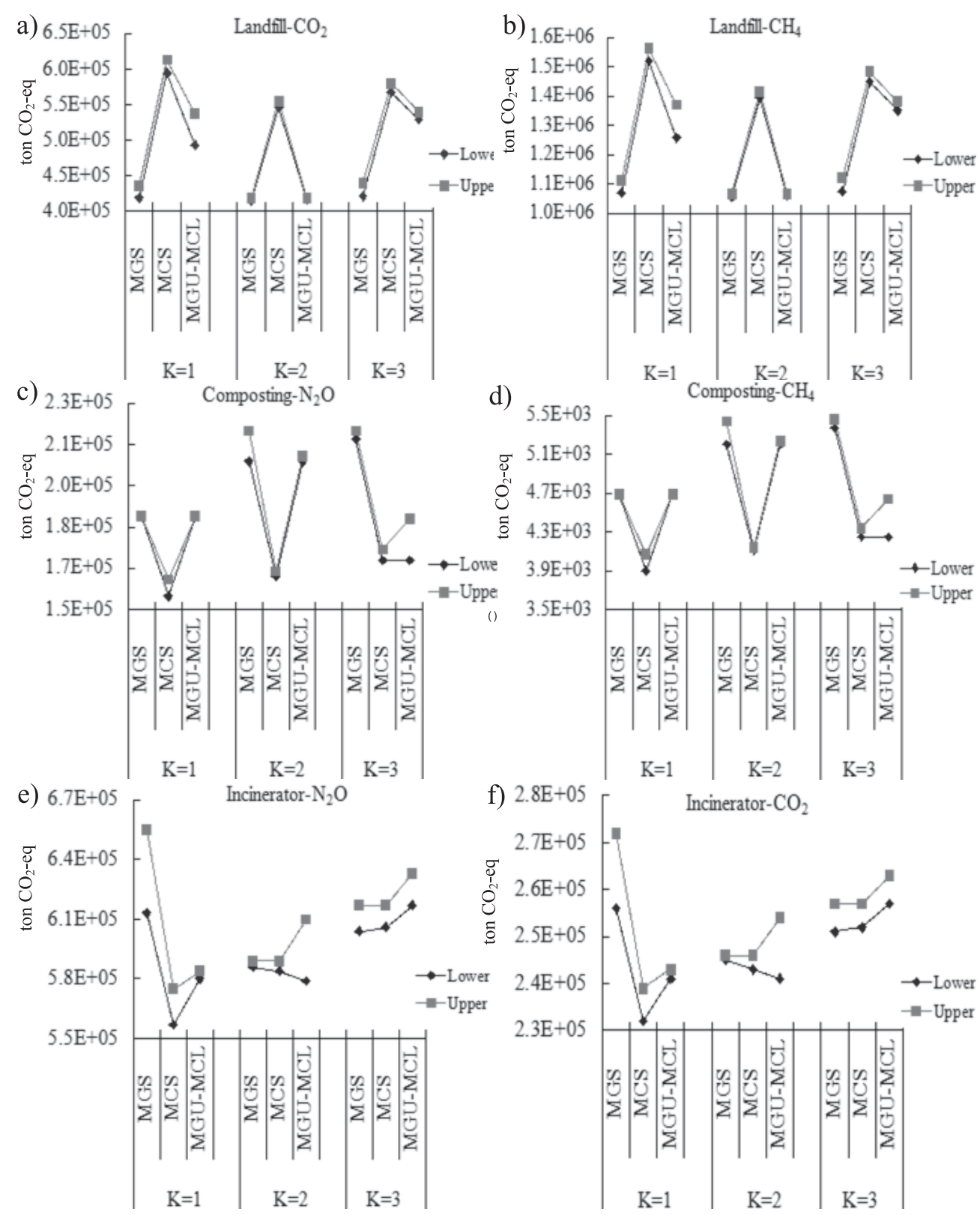

Fig. 7. GHG emissions from the different treatment facilities under the three models (Unit: $\mathrm{CO}_{2}$-eq).

to $\mathrm{N}_{2} \mathrm{O}$ is predominant. The allocation schemes generated from the three models visually reflect the variations of GHG emissions (Fig. 7). The $\mathrm{CO}_{2}$ and $\mathrm{CH}_{4}$ emissions from landfill facilities based on the MCS would exceed that based on the MGS and the MGU-MCL. In detail, the optimized $\mathrm{CO}_{2}$ and $\mathrm{CH}_{4}$ emissions under the MCS scheme would reach $[17.09,17.48] \times 10^{5}$ tons $\mathrm{CO}_{2}$-eq and $[43.65$, $44.64] \times 10^{5}$ tons $\mathrm{CO}_{2}$-eq, with [35.06, 36.28]\% and [16.80, $18.90] \%$ more than that under the MGS scheme and the MGU-MCL scheme, respectively.

Unlike the allocation scheme obtained from the MCS, more waste flows would be sent to the composting and incineration facilities according to the MGS and the MGU-MCL schemes. As a result, the GHG-emission (primarily $\mathrm{N}_{2} \mathrm{O}$ ) in terms of the MGS and the MGU-MCL would exceed that in terms of the MCS. For instance, the MGS only seeks eivironmental benefit so that composting facilities would handle approximately $38 \%$ of the waste flows, which significantly exceeds their preset diversion rate (i.e., 30\%). Consequently, a high diversion rate correponds to increased waste that would be treated in the composting and incineration facilities, then to higher GHG emissions in the two process units, particularly $\mathrm{N}_{2} \mathrm{O}$. The incineration facility is the second-largest source for the GHG-emission after landfill facility, primarily due to regulation from the management policy of Beijing.

(4) Economic cost analysis. Fig. 8 presents the comparison of economic cost among the three models, through which the effects of waste diversion on MSW management cost can be examined. Under the MGS conditions, the economic cost would be $\$[59.5$, $89.1] \times 10^{8}$ over the entire planning horizon, which is $13.94 \%$ greater than that from the MCS. The economic cost from the MGU-MCL model would amount 
to $\$[57.3,85.5] \times 10^{8}$, about $4 \%$ lower than that from the MGS scheme or $8 \%$ more than that from the MCS scheme. In the MGU-MCL decision, about $65 \%$ of the total system cost would come from incineration and composting facilities because of their processing more than $70 \%$ of the generated waste in the study area. Similarly, the transfer stations would contribute $24 \%$ of the total. By contrast, landfill facility would play an insignificant role in economic contribution, accounting for approximately $3.5 \%$.

(a) MGS

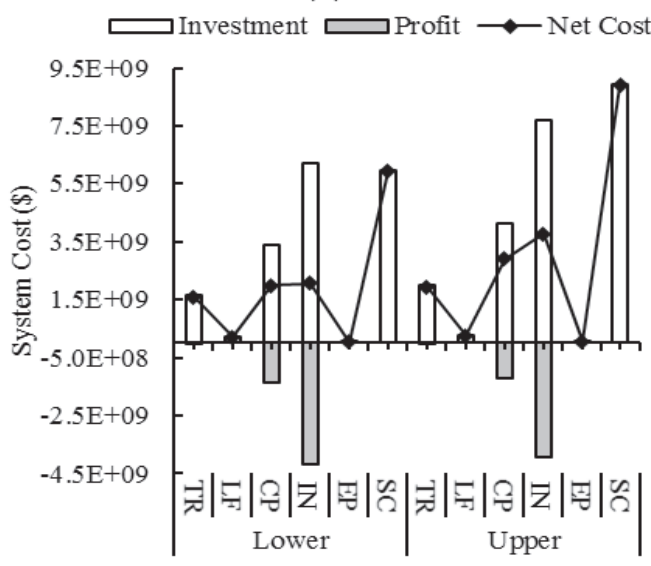

(b) MCS

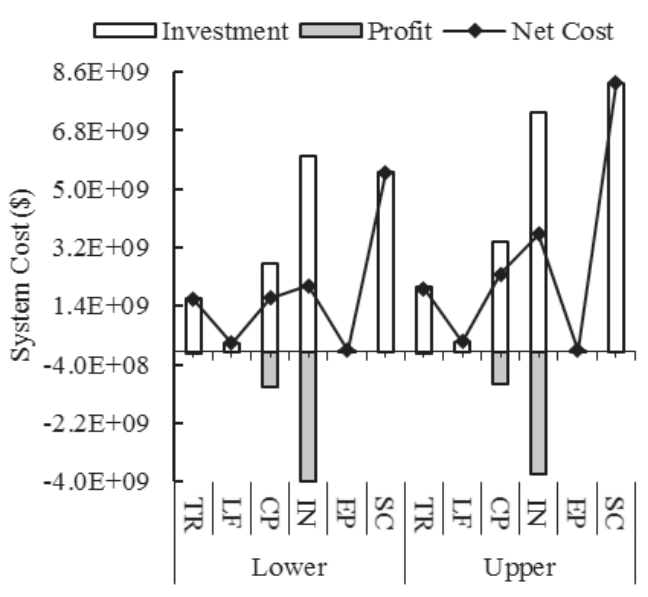

(c) MGU-MCL

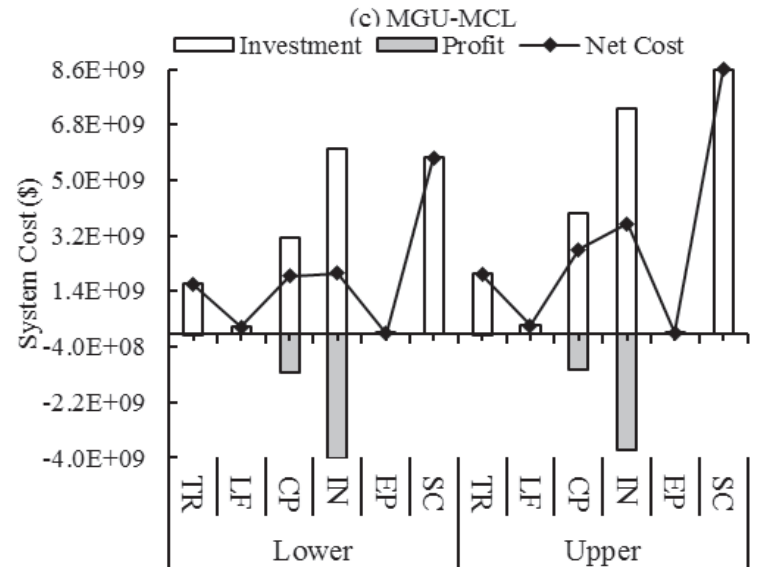

Fig. 8. System cost under the three models (Unit: \$).

\section{Waste-management Efficiency Analysis and Policy Analysis}

The estimated diversion rate, GHG-emission, economic cost, and equipment utilization are selected as the indices for analyzing waste-management efficiency and policy, as shown in Table 6. Results show that a higher diversion rate is aligned to more GHG emissions reduction and economic cost, but irrational facility-expansion schemes would be performed, leading to lower equipment utilization. Additionally, the GHG emissions from the MCS scheme would increase to $88.00 \times 10^{3}$ tons $\mathrm{CO}_{2}$-eq $/(\mathrm{kt} \cdot \mathrm{MSW})$, which hardly satisfies the objective of the decisionmaker of the environmental sector. Actually, comparative analysis of the three models indicates that the MGU-MCL scheme reflects slightly increased management cost, yet a high level of equipment utilization and diversion rate. Generally, in environmental sector terms the scheme acquired from the MGS approach would be prioritized, whereas the scheme achieved through the MCS would be selected from the perspective of local authority. When the decision-makers demonstrate a moderate attitude toward environmental effects and economic cost, the scheme from the MGU-MCL approach would be the primary option.

Moreover, landfill facility plays an irreplaceable role in the MSW management system. It is the largest contributor to GWP impacts. Conversely, its cost is the lowest among the process units. Thus, landfilling gas utilization is suggested as the best way to control GHG emissions and economic cost. Similar conclusions were also drawn in the literature [17]. Particularly in Beijing, the proportion of landfilling (e.g., $25 \%$ suggested by the MGU-MCL) would be reduced, and the existing landfill facilities must make full utilization of their landfilling gas. Also, development or expansion composting and incineration facilities would be given much importance given their equipment utilization being improved.

\section{Discussion and Conclusions}

This study develops an MGU-MCL model with two objective functions, namely to minimize GHG emissions expressed as GWP impacts at the environmental sector level and to minimize MSW management costs at the local authority level. This is the first attempt to apply the MGUMCL model for dealing with control of GHG emissions, economic cost, and waste resource utilization in an actual case: the MSW management system in the city of Beijing. Moreover, implicit in the model allocation scheme is the fact that the MGU-MCL schemes reduce GHG emissions by $9 \%$ yet increase $4 \%$ of the total management cost as compared with the conventional MCS model. The MGUMCL schemes become the most favorable among the three models because of their modest diversion rate, high level of equipment utilization, and contribution to GHG emissions mitigation, while uncertainties over GWP impact value and diversion rate of MSW would have significant impacts on the bi-level decisions. 
Table 6. MSW management efficiency of the three models.

\begin{tabular}{|c|c|c|c|c|c|c|c|}
\hline \multirow{2}{*}{ Index } & \multirow{2}{*}{$\begin{array}{c}\text { Diversion rate } \\
(\%)\end{array}$} & \multirow{2}{*}{$\begin{array}{c}\text { GHG } \\
\end{array}$} & $\left(10^{3}\right.$ ton $\mathrm{CO}_{2}$-eq $\left./ \mathrm{kt} \cdot \mathrm{MSW}\right)$ & \multirow{2}{*}{$\begin{array}{c}\text { Economic cost } \\
\left(10^{3} \$ / \mathrm{kt} \cdot \mathrm{MSW}\right)\end{array}$} & \multicolumn{4}{|c|}{ Equipment utilization (\%) } \\
\cline { 5 - 9 } & MGS & 77.08 & 68.30 & 45 & 88 & 69 & 67 \\
\hline MCS & 71 & 88.00 & 63.00 & 62 & 75 & 76 & 71 \\
\hline MGU-MCL & 75 & 82.10 & 65.76 & 55 & 87 & 70 & 71 \\
\hline
\end{tabular}

Note: $\mathrm{LF}=$ landfill; $\mathrm{CP}=$ composting facility; $\mathrm{IN}=$ incineration facility.

The MGU-MCL model could be improved in future studies. For instance, some types of GHGs (e.g., CO and $\mathrm{SO}_{2}$ ) were not considered due to low emission levels during the MSW disposal processes. Additionally, the interaction among the GHGs was neglected, which may slightly affect the optimized schemes. Therefore, future studies must be conducted to improve the current model and to accommodate the increased complexity in MSW management and GHG emissions control.

\section{Acknowledgements}

This research was supported by the Program for China National Funds for Excellent Young Scientists (51422903), the National Natural Science Foundation of China (41271540), the New Century Excellent Talents in Universities of China (NCET-13-0791), and Fundamental Research Funds for the Central Universities.

\section{Appendix}

$t$ : Index for transfer station, $t=1,2 \ldots 6$

$l$ : Index for landfill, $l=1,2 \ldots 13$

$c$ : Index for composting, $\mathrm{c}=1,2 \ldots 5$

$i$ : Index for incinerator, $i=1,2 \ldots .5$

$k$ : Index for planning period, $k=1,2,3$

$j$ : Index for districts, $j=1,2 \ldots 18, j=1$ for Dongcheng,

2 for Xicheng, 3 for Chongwen, 4 for Xuanwu, 5 for Chaoyang, 6 for Fengtai, 7 for Shijingshan, 8 for Haidian, 9 for Mentouguo, 10 for Fangshan, 11 for Tongzhou, 12 for Shunyi, 13 for Changping, 14 for Daxing, 15 for Pinggu, 16 for Huairou, 17 for Miyun, 18 for Yanqing

$e$ : Index for transfer station expansion option, $e=1,2,3$

$m$ : Index for composting expansion option, $m=1,2,3$

$n$ : Index for incinerator expansion option, $n=1,2,3$

$X T^{ \pm} t, k$ : Waste flow from urban districts to transfer station $t$ in period $k$ (ton/day)

$X L^{ \pm} t, l, k$ : Waste flow from transfer station $t$ to landfill $l$ during period $k$ (ton/day)

$X U L_{l, k}^{ \pm}$: Waste flow from districts to landfill $l$ during period $k$ (ton/day)

$X C^{ \pm}{ }_{t, c, k}$ : Waste flow from transfer station $t$ to composting $c$ in period $k$ (ton/day)

$X U C^{ \pm}{ }_{c, k}$ : Waste flow from districts to composting $c$ during period $k$ (ton/day)
$X I_{t, i, k}^{ \pm}$: Waste flow from transfer station $t$ to incinerator $i$ during period $k$ (ton/day)

$X U I^{ \pm}{ }_{i, k}$ : Waste flow from districts to incinerator $i$ during period $k$ (ton/day)

$X R C^{ \pm}{ }_{c, l, k}$ : Residue MSW from composting $c$ to landfill $l$ during period $k$ (ton/day)

$X R I^{ \pm}{ }_{i, l, k}$ : Residue MSW from incinerator $i$ to landfill $l$ during period $k$ (ton/day)

$Y_{t, e, k^{k}}$ : Binary variable for transfer station $t$ with option $e$ during period $k$

$U_{c, m, k}$ : Binary variable for composting $c$ with option $m$ during period $k$

$Z_{i, n, k}$ : Binary variable for incinerator $i$ with option $n$ during period $k$

$T G W P^{ \pm}$: Total emissions of metric ton carbon equivalent (ton $\mathrm{CO}_{2}$-eq)

TCOST ${ }^{ \pm}$: Net system cost $(\$)$

$L_{k}$ : Length of period $k$ (day)

$G W P_{t r k}^{ \pm}$: Unit GWP for transportation of per MSW during period $k$ ( $\mathrm{kg} \mathrm{CO}_{2}$-eq /ton)

$G W P_{t, k}^{ \pm}$: Unit GWP for transfer station of per MSW in period $k$ ( $\mathrm{kg} \mathrm{CO}_{2}$-eq /ton)

$G W P_{l, k}^{ \pm}$: Unit GWP for landfill of per MSW during period $k(\mathrm{~kg} \mathrm{CO}-$ eq /ton $)$

$G W P_{c, k}^{ \pm}$: Unit GWP for composting of per MSW during period $k$ ( $\mathrm{kg} \mathrm{CO}_{2}$-eq /ton)

$G W P_{i, k}^{ \pm}$: Unit GWP for incinerator of per MSW during period $k$ ( $\mathrm{kg} \mathrm{CO}_{2}$-eq /ton)

$T S T_{k}$ : Environmental standard level during period $k(\mathrm{~kg}$ $\mathrm{CO}_{2}$-eq /day)

$C C^{ \pm}{ }_{k}$ : Collection costs during period $k(\$ /$ ton $)$

$T R^{ \pm}{ }_{k}$ : Transportation costs during period $k$ (\$/ton)

$O T^{ \pm}{ }_{t, k}$ : Operating costs of transfer station $t$ during period $k$ (\$/ton)

$O L_{l, k}^{ \pm}$: Operating costs of landfill $l$ during period $k$ (\$/ton)

$O C^{ \pm}{ }_{c, k}$ : Operating costs of composting facility $c$ during period $k$ (\$/ton)

$O I^{ \pm}{ }_{i, k}$ : Operating costs of incinerator $i$ during period $k(\$ /$ ton)

$F T_{t, k}$ : Residue rates of transfer station $t$ during period $k(\%)$

$F C_{c, k}$ : Residue rates of composting facility $c$ during period $k(\%)$

$F I_{i, k}:$ Residue rates of incinerator $i$ during period $k(\%)$

$\xi$ : Biogas generation of per MSW $(\mathrm{kW} \cdot \mathrm{h} /$ ton $)$

$P C E^{ \pm}$: : Biogas generation cost $(\$ / \mathrm{kW} \cdot \mathrm{h})$

$G C E^{ \pm}{ }_{k}$ : Costs of air control for biogas generation during period $k(\$ / \mathrm{kW} \cdot \mathrm{h})$

$\psi$ : Incineration power generation of per MSW $(\mathrm{kW} \cdot \mathrm{h} /$ ton $)$ 
$P I E^{ \pm}{ }_{i, k}$ : Incineration power generation cost $(\$ / \mathrm{kW} \cdot \mathrm{h})$

$G I E^{ \pm}{ }_{k}$ : Cost for air control in incineration during period $k$ $(\$ / \mathrm{kW} \cdot \mathrm{h})$

$F C C^{ \pm}{ }_{m, k}$ : Cost for composting facility expansion with option $m$ during period $k(\$)$

$F C I^{ \pm}{ }_{n, k}$ : Cost for incinerator expansion with option $n$ during period $k(\$)$

$F C T_{e, k}^{ \pm}$: Cost for transfer station expansion with option $e$ during period $k(\$)$

$R T_{t, k}^{ \pm}$: Recycle revenue of transfer station $t$ during period $k(\$ /$ ton $)$

$R C^{ \pm}{ }_{c, k}$ : Recycle revenue of composting facility $c$ during period $k(\$ /$ ton $)$

$R C E^{ \pm}$: Revenue from biogas generation during period $k$ $(\$ / \mathrm{kW} \cdot \mathrm{h})$

$P C F^{ \pm}$: Rertilizer revenue from composting facility during period $k(\$ /$ ton $)$

$\Omega$ : Fertilizer production efficiency ( $\%)$

$R I^{ \pm}{ }_{i k}$ : Recycle revenue of incinerator $i$ during period $k(\$ /$ ton)

$G R I^{ \pm}$: Government subsidies to incineration facility during period $k$ (\$/ton)

$R I E^{ \pm}{ }_{k}$ : Revenue from incineration power generation during period $k(\$ / \mathrm{kW} \cdot \mathrm{h})$

$T L C^{ \pm}$: Capacity of landfill $l$ at the start of planning period (ton/day)

$S L C^{ \pm}$: Minimum processing capacity of landfill $l$ (ton/day)

$T C_{t}$ : Capacity of transfer station $t$ at the start of planning period (ton/day)

$\Delta T C_{e, k}$ : Capacity expansion with option $e$ for transfer station $t$ in period $k$ (ton/day)

$S C_{t}$ : Minimum processing capacity of transfer station $t$ (ton/day)

$T C C_{c}$ : Capacity of composting facility $c$ at the start of planning period (ton/day)

$S C C$ : Minimum processing capacity of composting facility $c$ (ton/day)

$\Delta T C C_{c^{\prime} m, k}$ : Capacity expansion with option $m$ for composting $c$ in period $k$ (ton/day)

$T I C_{i}$ : Capacity of incinerator $i$ at the start of planning period (ton/day)

$\triangle T I C_{i n, k}$ : Capacity expansion with option $n$ for incinerator $i$ in period $k$ (ton/day)

$S I C_{i}$ : Minimum processing capacity of incinerator $i$ (ton/ day)

$W_{j, k}^{ \pm}$: Amount of waste generated in district $j$ during period $k$ (ton/day)

$T S W^{ \pm}$: Total amount of waste generated in Beijing during period $k$ (ton/day)

$G T_{k}$ : Diversion rate of waste flow to transfer station during period $k(\%)$

$G I_{k}$ : Diversion rate of waste flow to incinerator during period $k(\%)$

$G C_{k}$ : Diversion rate of waste flow to composting facility during period $k(\%)$

$G L_{k}$ : Diversion rate of waste flow to landfill during period $k(\%)$

\section{References}

1. CHEN C.W., HUANG G.H. Artificial intelligence for management and control of pollution minimization and mitigation processes. Engineering Applications of Artificial Intelligence 16, 75, 2003.

2. CORSTEN M., WORRELL E., ROUR M., DUIN A. The potential contribution of sustainable waste management to energy use and greenhouse gas emission reduction in the 26 Netherlands. Resources Conservation and Recycling 77, 13, 2013.

3. HE L., HUANG G.H., LU H.W. Bivariate interval semiinfinite programming with an application to environmental decision-making analysis. European Journal of Operational Research 211, 452, 2011 a.

4. LU H.W., HUANG G.H., XU Y., HE L. Inexact two-phase fuzzy programming and its application to municipal solid waste management. Engineering Applications of Artificial Intelligence 25, 1529, 2012.

5. BATOOL S.A., CHUADHRY M.N. The impact of municipal solid waste treatment methods on greenhouse gas emissions in Lahore, Pakistan. Waste Management 29, 63, 2009.

6. LIAMSANGUAN C., GHEEWALA S.H. The holistic impact of integrated solid waste management on greenhouse gas emissions in Phuket. Journal of Cleaner Production 16, 1865, 2008.

7. BRASCHEL N., POSCH A. A review of system boundaries of GHG emission inventories in waste management. Journal of Cleaner Production 44, 30, 2013.

8. PARK S.W., CHOI J.H., PARK J.W. The estimation of $\mathrm{N}_{2} \mathrm{O}$ emissions from municipal solid waste incineration facilities: The Korea case. Waste Management 31, 1765, 2011.

9. MOHAREB A.K., WARITH M.A., DIAZ R. Modelling greenhouse gas emissions for municipal solid waste management strategies in Ottawa, Ontario, Canada. Resources, Conservation and Recycling 52, 1241, 2008.

10. USEPA (U.S. Environmental Protection Agency). Inventory of U.S. Greenhouse Gas Emissions and Sinks: 1990-2008. U.S. Environmental Protection Agency, Washington, DC, USA, 2010.

11. LU H.W., SUN S.C., REN L.X., HE L. GHG emission control and solid waste management for megacities with inexact inputs: A case study in Beijing, China. Journal of Hazardous Materials 284, 92, 2015.

12. WANG Y., HE Y., YAN B.B., MA W.C., HAN M. Collaborative emission reduction of greenhouse gas emissions and municipal solid waste management: case study of Tianjin. Procedia Environmental Sciences 16, 75, 2012.

13. EL-FADEL M., SBAYTI H. Economics of mitigating greenhouse gas emissions from solid waste in Lebanon. Waste Manage Research 18, 329, 2000.

14. WEITZ K.A., THORNELOE S.A., NISHTALA S.R., ZANNES $M$. The impact of municipal solid waste management on greenhouse gas emissions in the United States. Journal of the Air \& Waste Management Association 52, 1000, 2011.

15. LI Y.P., HUANG G.H. An interval-based possibilistic programming method for waste management with cost minimization and environmental-impact abatement under uncertainty. Science of the Total Environment 408, 4296, 2010.

16. CHANG N.B., QI C., ISLAM K., HOSSAIN F. Comparisons between global warming potential and cost-benefit criteria for optimal planning of a municipal solid waste management system. Journal of Cleaner Production 20, 1, 2012. 
17. ZHAO W., HIPPES G., VOET E.V.D. Eco-efficiency for greenhouse gas emissions mitigation of municipal solid waste management: A case study of Tianjin, China. Waste Management 31, 1407, 2011.

18. LU H.W., HUANG G.H., HE L., ZENG G.M. An inexact dynamic optimization model for municipal solid waste management in association with greenhouse gas emission control. Journal of environmental management 90, 396, 2009.

19. SU J., XI B.D., LIU H.L., JIANG Y.H., WARITH M.A. An inexact multi-objective dynamic model and its application in China for the management of municipal solid waste. Waste Management 28, 2532, 2008.

20. MAVROTAS G., SKOULAXINOU S., GAKIS N., KATSOUROS V., GEORGOPOULOU E. A multi-objective programming model for assessment the GHG emissions in MSW management. Waste Management 33, 1934, 2013.

21. CALVETE H.I., GALE C. Linear bilevel programs with multiple objectives at the upper level. Journal of Computational and Applied Mathematics 234, 950, 2010.

22. AVISO K.B., TAN R.R., CULABA A.B., CRUZ JR J.B., Bi-level fuzzy optimization approach for water exchange in eco-industrial parks. Process Safety and Environmental Protection 88, 31, 2010.

23. GANG J., TU Y., LEV B., XU J.P., SHEN W.J., YAO L.M. A multi-objective bi-level location planning problem for stone industrial parks. Computers \& Operations Research 56, 8, 2015.

24. TAHA A.F., HACHEM N.A., PANCHAL J.H. A QuasiFeed-In-Tariff policy formulation in micro-grids: A bi-level multi-period approach. Energy Policy 71, 63, 2014.

25. HE L., HUANG G.H., LU H.W. Greenhouse gas emissions control in integrated municipal solid waste management through mixed integer bilevel decision-making. Journal of Hazardous Materials 193, 112, 2011b.

26. KALASHNIKOV V.V., PEREZ-VALDES G.A., TOMASGARD A., KALASHNYKOVA N.I. Natural gas cash-out problem: Bilevel stochastic optimization approach. European Journal of Operational Research 206, 18, 2010.

27. XIE Y.L., LI Y.P., HUANG G.H., CHEN L.R. An inexact chance-constrained programming model for water quality management in Binhai New Area of Tianjin, China. Science of the Total Environment 409, 1757, 2011.

28. DAI C., LI Y.P., HUANG G.H. A two-stage support-vectorregression optimization model for municipal solid waste management - A case study of Beijing, China. Journal of Environmental Management 92, 3023, 2011.

29. National Bureau of Statistics of China (NBS), China Statistical Yearbook 2004-2013. China Statistics Press, Beijing, China. 2005-2014 (in Chinese).

30. SHIH H.S., LEE E.S. A fuzzy possibilistic approach to multi-level optimization. The Eighth Annual Industrial Engineering Research Conference 23, 1999.

31. KASPERSKI A. A possibilistic approach to sequencing problems with fuzzy parameters. Fuzzy Sets and Systems 150, 77, 2005.

32. EMAM O.E. A fuzzy approach for bi-level integer nonlinear programming problem. Applied Mathematics and Computation 172, 62, 2006.

33. HUANG G.H., BAETZ B.W., PARTY G.G. Grey integer programming: an application to waste management planning under uncertainty. European Journal of Operational Research 83, 594, 1995.

34. BELLMAN R.E., ZADEH L.A. Decision making in a fuzzy environment. Mgmt. Sci. 17B, 141, 1970.

35. MAQSOOD I., HUANG G.H., YEOMANS J.S. An intervalparameter fuzzy two-stage stochastic program for water resources management under uncertainty. European Journal of Operational Research 167, 208, 2005.

36. GUO P., HUANG G.H. Interval-parameter semi-infinite fuzzy-stochastic mixed-integer programming approach for environmental management under multiple uncertainties. Waste Management 30, 521, 2010. 